OPEN ACCESS

Edited by:

Si Wu,

Beijing Normal University, China

Reviewed by:

Xiaoli Li,

Beijing Normal University, China

Duan Li,

University of Michigan, United States

*Correspondence:

Diego Lozano-Soldevilla

diegols@protonmail.com

orcid.org/0000-0003-1794-8204

Received: 15 December 2017 Accepted: 20 March 2018

Published: 04 April 2018

Citation:

Lozano-Soldevilla D (2018) On the Physiological Modulation and Potential Mechanisms Underlying

Parieto-Occipital Alpha Oscillations. Front. Comput. Neurosci. 12:23. doi: $10.3389 /$ fncom.2018.00023

\section{On the Physiological Modulation and Potential Mechanisms Underlying Parieto-Occipital Alpha Oscillations}

\author{
Diego Lozano-Soldevilla* \\ Institut d'Investigacions Biomèdiques August Pi i Sunyer, Barcelona, Spain
}

The parieto-occipital alpha $(8-13 \mathrm{~Hz})$ rhythm is by far the strongest spectral fingerprint in the human brain. Almost 90 years later, its physiological origin is still far from clear. In this Research Topic I review human pharmacological studies using electroencephalography (EEG) and magnetoencephalography (MEG) that investigated the physiological mechanisms behind posterior alpha. Based on results from classical and recent experimental studies, I find a wide spectrum of drugs that modulate parieto-occipital alpha power. Alpha frequency is rarely affected, but this might be due to the range of drug dosages employed. Animal and human pharmacological findings suggest that both GABA enhancers and NMDA blockers systematically decrease posterior alpha power. Surprisingly, most of the theoretical frameworks do not seem to embrace these empirical findings and the debate on the functional role of alpha oscillations has been polarized between the inhibition vs. active poles hypotheses. Here, I speculate that the functional role of alpha might depend on physiological excitation as much as on physiological inhibition. This is supported by animal and human pharmacological work showing that GABAergic, glutamatergic, cholinergic, and serotonergic receptors in the thalamus and the cortex play a key role in the regulation of alpha power and frequency. This myriad of physiological modulations fit with the view that the alpha rhythm is a complex rhythm with multiple sources supported by both thalamo-cortical and cortico-cortical loops. Finally, I briefly discuss how future research combining experimental measurements derived from theoretical predictions based of biophysically realistic computational models will be crucial to the reconciliation of these disparate findings.

Keywords: magnetoencephalography, electroencephalography, brain oscillations, pharmacology, cognitive processes

\section{INTRODUCTION}

The alpha rhythm is by far the most prominent spectral fingerprint of the human brain. Almost 90 years later, its mechanism and sources still remain elusive. As mysterious as its physiology, the discovery of the alpha rhythm was driven by Hans Berger's belief that electromagnetic brain activity could be the biological substrate behind telepathy (Millett, 2001). To investigate his hypotheses, he set in motion an ambitions human electrophysiology research program 
which led to the invention of the most employed non-invasive electrophysiological method-the electroencephalogram (EEG). It was the possibility to record brain activity through EEG that paved the way for the subsequent discovery of human brain rhythms. He reported "waves of first order": the fascinating waxing and waning $10 \mathrm{~Hz}$ periodicity produced in relaxed but awake participants (Berger, 1929). Adrian and Mathews replicated and extended Berger's original findings. They showed, amongst other things, how water-beetles suppress their alpha amplitude in response to light, or how flicker stimulation can entrain the intrinsic alpha rhythm - thus making a case for its cortical origins (Adrian and Matthews, 1934).

Years later, human invasive EEG studies confirmed the existence of alpha oscillations in subcortical brain regions such as the thalamus (Gücer et al., 1978) and the pulvinar nuclei (Albe-Fessard et al., 1966; Albe-Fessard, 1973). In trying to disentangle the thalamo-cortical interactions, Lopes da Silva found the coherence between pulvinar and visual cortex to be much stronger than the coherence between the lateral geniculate nucleus (LGN) and the cortex (Lopes da Silva et al., 1973b). Interestingly, cortico-cortical coherence remained high after partializing the thalamic contribution (Lopes da Silva et al., 1973b), suggesting at least two independent sources. The cognitive relevance of the pulvinar-to-cortex circuitry was convincingly demonstrated 39 years later. Saalmann et al. (2012) revealed that the pulvinar plays a key role in setting the frequency of neuronal communication between $\mathrm{V} 4$ and the temporooccipital area (TEO) to around $10 \mathrm{~Hz}$ when monkeys allocated their attention to a visual target.

Taking together, the neural circuitry behind posterior alpha rhythm seems rather complex, with thalamic and cortical sources contributing independently, and presumably influencing each other (Lopes da Silva, 1991). Indirectly, the complexity underlying the alpha rhythm can be grasped from the limited amount of in-vitro and in-vivo models (Silva et al., 1991; Hughes et al., 2004, 2011; Lörincz et al., 2008, 2009) relative to other rhythms whose neural circuitry essentially relies on local connectivity, such as beta and gamma (Traub and Miles, 1991; Traub et al., 1999; Traub and Whittington, 2010).

In this invited review, I will first discuss some methodological challenges common in pharmacological studies employing EEG and magnetoencephalography (MEG) and I will propose useful ways to approach them. Second, I will cover recent animal electrophysiology studies and EEG and MEG pharmacological challenges (pharmaco-MEEG) to illustrate how diverse neuromodulators can influence the posterior alpha rhythm. Regarding the pharmaco-MEEG evidence, I will focus on studies that employed drugs affecting GABA, glutamate, acetylcholine, and serotonin in healthy control participants during resting and task conditions. Third, I will discuss these empirical findings in relation to current theoretical frameworks to discuss how well the functional role of the alpha rhythm fits with its physiological modulations. Lastly, I will discuss the need to develop biophysically realistic computational models which can generate realistic predictions to guide the next generation of pharmaco-MEEG studies.

\section{PARIETO-OCCIPITAL ALPHA OSCILLATIONS ARE MODULATED BY A MYRIAD OF PHARMACOLOGICAL AGENTS}

\section{GABAergic Enhancement Decreases Parieto-Occipital Alpha Power}

The link between the alpha rhythm and physiological inhibition is long-established. During the 60's, Andersen and Andersson performed a series of pharmacological experiments in anesthetized cats to elucidate the physiological basis of the alpha rhythm. Employing barbiturates, potent GABAergic agonists, they were able to create an animal model that produced robust spindling activity with very similar frequency as the resting alpha. They claimed that the occipital resting alpha was mainly contributed by a thalamic pacemaker constituted by inhibitory neurons that project into the cortex (Andersen and Andersson, 1968). Years later, ground-breaking work by Fernando Lopes da Silva convincingly demonstrated that the proposed barbiturate-induced spindle activity and the classical alpha rhythm were two different physiological phenomena (Lopes da Silva et al., 1973a, 1980). Notably, the barbiturateinduced spindle activity was topographically more widespread than the posterior alpha, the wave duration was shorter and the thalamo-cortical coherence stronger (Lopes da Silva et al., 1973a). Mircea Steriade, a world leading authority on the cellular basis of brain rhythms, summarized the issue as follows:"The temptation to understand the mechanisms of this rhythm at the cellular level by recording spindle oscillations under barbiturate anesthesia (Andersen and Andersson, 1968) is understandable, but alpha and spindle waves are quite different oscillations. Indeed, while the frequencies of these two rhythms may overlap, their origins and especially their behavioral context are dissimilar" (Steriade, 1999). These findings relaxed the alpha pacemaker hypothesis, establishing the thalamus as a prominent alpha source (Lopes da Silva et al., 1973a,b, 1980) in addition to occipital sources (Lopes da Silva and Storm Van Leeuwen, 1977).

Pharmaco-MEEG has employed a variety of anesthetics and barbiturates known to potentiate the effect of GABA to study its effect on alpha oscillations. Propofol, for example, is a popular anesthetic that binds to $\mathrm{GABA}_{\mathrm{A}}$ receptors producing a strong hyperpolarization as a consequence of the opening of chloride channel in pyramidal neurons (Bai et al., 1999). This hyperpolarization led to a loss of consciousness, which is characterized by a prominent alpha power increase in frontal sensors with a concurrent posterior alpha power decrease (Ching et al., 2010; Cimenser et al., 2011; Supp et al., 2011; Purdon et al., 2013), a process coined as "anteriorization" (Feshchenko et al., 2004). Other drugs, such the benzodiazepines, are not agonists but allosteric modulators: they need the presence of GABA neurotransmitter in the synaptic cleft to produce the hyperpolarization. Relative to anesthetics and barbiturates, benzodiazepines produce milder sedative effects and have lower risk of over dosage. They bind to $\mathrm{GABA}_{\mathrm{A}}$ receptors and enhance chloride conductance by increasing its channel-opening 
frequency (Riss et al., 2008), as opposed to maintaining the channels open (as anesthetics and barbiturates do). Interestingly, a large variety of benzodiazepine type drugs using a wide range of dosages have been shown to produce a consistent decrease in parieto-occipital alpha power during resting state (Fink et al., 1976; Bond and Lader, 1982; Golombok and Lader, 1984; Koopmans et al., 1988; Van Steveninck et al., 1993; Feshchenko et al., 1997; Liley et al., 2003; Boeijinga et al., 2004; Fingelkurts et al., 2004; Schreckenberger et al., 2004; Connemann et al., 2005; Ahveninen et al., 2007; Yoto et al., 2012; Alonso et al., 2015; Nutt et al., 2015; Lozano-Soldevilla et al., 2016) and task conditions (van Leeuwen et al., 1995; Gevins et al., 2002; MuñozTorres et al., 2011; Saxena et al., 2013; Lozano-Soldevilla et al., 2014). Reports of benzodiazepine studies finding posterior alpha power increases (Tran et al., 2004; Nikulin et al., 2005; Hall et al., 2010; Nutt et al., 2015), frequency modulations (Liley et al., 2003), or just null results (Urata et al., 1996; Jensen et al., 2005; Muthukumaraswamy et al., 2013b; Campbell et al., 2014) are less common within the literature. In conclusion, pharmacologically increasing GABA efficacy leads to a decrease in power of the classical alpha-but, what is the underlying mechanism?

\section{Are Posterior Alpha Oscillations Implemented by Physiological Inhibition, Excitation, or a Balance Between the Two?} Current theoretical frameworks assign alpha oscillations a functional inhibitory role. In this case, alpha power should exert functional inhibition on those brain regions, time periods or cognitive representations that need to be suppressed to optimally perform the task at hand (Klimesch et al., 2007; Jensen and Mazaheri, 2010; Mazaheri and Jensen, 2010; Foxe and Snyder, 2011; Mathewson et al., 2011; Weisz et al., 2011; Jensen et al., 2012, 2014; Klimesch, 2012; Womelsdorf et al., 2014). At the other extreme of the continuum, numerous studies have found that alpha performs an active role in numerous cognitive operations (Palva and Palva, 2007, 2011; Womelsdorf et al., 2014). These frameworks demonstrate a remarkable and parsimonious link between oscillatory activity and behavior. Through them, one can explain a myriad of electrophysiological, cognitive, and behavioral findings obtained in a large variety of tasks and sensory modalities. Key to the present discussion, some frameworks assume that the functional inhibition reflected in the alpha band is implemented through physiological inhibition (Klimesch et al., 2007; Jensen and Mazaheri, 2010; Mazaheri and Jensen, 2010; Jensen et al., 2012, 2014). More specifically, alpha oscillations could represent physiological inhibition generated by GABAergic interneurons and they could tax neuronal processing indexed by neuronal firing. This inhibition reflected in the alpha band has been modeled as a thalamic drive whose GABA conductance changes sinusoidally at $10 \mathrm{~Hz}$ (Gips et al., 2016). Alpha phase could play a fundamental role in segmenting visual information as a function of neuronal excitability: with more excitable cells firing earlier within the alpha cycle as this would allow them to code more salient stimuli (Jensen et al., 2012, 2014). See (Gips et al., 2016) for a computation implementation of the idea. Thereby, functional inhibition could be a consequence of physiological "pulsed" inhibition produced by GABAergic feedback carried by interneurons within the cortex or the thalamus (Jensen and Mazaheri, 2010; Mazaheri and Jensen, 2010). Other recent frameworks, although highlighting the inhibitory role of alpha, widen the physiological hypothesis stressing the importance of the excitatory and inhibitory balance to control alpha amplitude and frequency (Klimesch, 2012; Himmelstoss et al., 2015). Other accounts stress that the crucial characteristic of alpha function is that it blocks the communication of local circuits due to its relatively slow period which precludes the action of fast inhibition (Fries, 2015). Finally, Womelsdorf et al. (2014) recent framework proposes the existence of two dynamical motifs that could account for the inhibitory and the active views of alpha. A motif is defined as a neural network composed of different cell types that produce different rhythms which perform specific neuronal computations. They propose a thalamic motif that amplifies that transmission of attended sensory information (active role), and a cortical motif in L6 that processes irrelevant information and is manifested due to the lack of thalamic excitatory input (inhibitory role).

There are indeed in-vivo animal models showing the importance of inhibitory interneurons in the modulation of $\sim 10 \mathrm{~Hz}$ rhythm in the somatosensory cortex and LGN (Fanselow and Nicolelis, 1999; Lörincz et al., 2009). In conclusion, if one follows the "alpha power reflects functional inhibition" principle, increasing the level of inhibition should lead to an increase of alpha power. The studies reviewed here indicate that pharmacological GABAergic enhancement decreases (rather than increases) the energy of the posterior alpha oscillations. This observation is not new and has indeed been acknowledged in the past:"Finally, we should also emphasize that one of the most straight forward tests of our hypothesis apparently leads to inconsistent results. The application of benzodiazepines (a GABA agonist) does not lead to increased alpha activity as one would expect if alpha is related to inhibitory activity but instead to a decrease in alpha" (Klimesch et al., 2007).

Most of the studies that used benzodiazepines and anesthetics recorded electrophysiological activity under resting state conditions. One may argue that the GABAergic modulations producing functional inhibition reflected within the alpha band could only be relevant (or measured) when the task at hand requires a strong top-down drive. Under these conditions, alpha power modulations have been shown to impact behavior in a variety of task and sensory modalities (Klimesch et al., 2007; Jensen and Mazaheri, 2010; Mazaheri and Jensen, 2010; Foxe and Snyder, 2011; Mathewson et al., 2011; Jensen et al., 2012, 2014; Klimesch, 2012).

Lozano-Soldevilla et al. (2014) designed a pharmaco-MEG study in humans to test this possibility. We combined MEG recordings testing two different dosages of lorazepam $(0.5,1.5 \mathrm{mg})$, a benzodiazepine that increases GABA efficacy. Participants performed a visuo-spatial working memory task where they had to allocate their locus of attention to a cued visual 
hemifield (1.5 s). After, a brief presentation ( $0.1 \mathrm{~s})$ of a sample stimulus of colored squares, participants had to memorize the color of the cued items while trying to ignore the non-cued items. After a $1.5 \mathrm{~s}$ delay, a second array appeared and participants decided whether the color of the items between the sample and the probe matched or not. This task is ideal to test the functional inhibition role of alpha during the allocation of attentional (cue period), memory maintenance and distractor suppression (delay period). Previous studies have repeatedly demonstrated that alpha power can be used as an electrophysiological proxy for the allocation of attention (Foxe et al., 1998; Worden et al., 2000; Thut et al., 2006; Händel et al., 2010; Foxe and Snyder, 2011). The increase of GABA efficacy leads two main predictions. First, if alpha is exerting its functional inhibition role through physiological inhibition, GABAergic enhancement should increase tonic alpha power. Second, this alpha power attentional modulations should increase parametrically with drug dosage. We found robust evidence in the opposite direction for both predictions. First, lorazepam strongly decreased both tonic alpha power and attentional power modulations (LozanoSoldevilla et al., 2014). Furthermore, we obtained an interaction between hemisphere and drug dosage specific to the delay interval. The interaction revealed that lorazepam caused an increased reduction in alpha power measured by the ipsilateral sensors relative to the contralateral sensors Figure 1a. What is the mechanism explaining the alpha power decrease with GABAergic enhancement? One possibility could be that the physiological bases of classical alpha oscillations rely on physiological excitation to a similar (or stronger) degree as physiological inhibition. Several lines of evidence support this speculation. In-vivo animal models have shown that pyramidal cells in the cortex have sufficient biophysical properties to produce alpha rhythm on their own (Steriade et al., 1990; Lopes da Silva, 1991; Silva et al., 1991; Castro-Alamancos and Connors, 1996; Flint and Connors, 1996). It is known that benzodiazepines decrease the number of spikes per burst, leaving the burst rate unaffected (Antkowiak, 1999). This finding could explain why benzodiazepines decrease alpha power without affecting its peak frequency.

It is interesting to note that very often the power dynamics underlying alpha and gamma oscillations tend to show opposite behavior. Regarding power modulations, while pharmacological GABAergic enhancement decreases alpha power, gamma power shows an increase (Oke et al., 2010; Xing et al., 2012a; Saxena et al., 2013; Campbell et al., 2014; Lozano-Soldevilla et al., 2014; Magazzini et al., 2016) but see (Muthukumaraswamy et al., 2013b,c). Stimulus-induced gamma power increase is often accompanied by alpha power decrease and this power asymmetry reverses in spontaneous conditions (Fries et al., 2001; Hoogenboom et al., 2006). A computational work proposes that this negative power relationship between high and low frequencies might be due to the ratio of the AMPA and NMDA conductances (Buehlmann and Deco, 2008; Deco and Thiele, 2009). Gamma oscillations seem to be located in more superficial layers while alpha is found to be stronger in infragranular layers (Bollimunta et al., 2008; Buffalo et al., 2011; Spaak et al., 2012; Xing et al., 2012b; van Kerkoerle et al., 2014; Bastos et al., 2015; Michalareas et al., 2016) but see (Haegens et al., 2015).
In conclusion, alpha and gamma rhythms seem to rely on complementary physiological mechanisms.

Another possibility would be that the alpha rhythm relies on the fine-grained excitation and inhibition (E/I) balance (Klimesch, 2012). The E/I balance has been intensively studied for faster rhythms during both spontaneous and stimulusevoked conditions (Anderson et al., 2000; Okun and Lampl, 2008). For example, there is compelling evidence showing that the instantaneous $\mathrm{E} / \mathrm{I}$ balance determines peak gamma frequency (Atallah and Scanziani, 2009). Similarly, recording EEG in a semantic judgement task, (Himmelstoss et al., 2015) showed that alpha frequency and amplitude covary: alpha period lengthened during high amplitude time windows Figure $\mathbf{1 b}$. If alpha amplitude is interpreted as instantaneous inhibition, the period of alpha must be slow. These results resemble the pyramidal-interneuron network gamma (PING) model. In this model, the minimum frequency is governed by the inhibitory time constant that prevents principal cells from firing (Tiesinga and Sejnowski, 2009). Unfortunately, these type of experimental models do not produce oscillations below $20 \mathrm{~Hz}$ (Traub et al., 1996).

Overall, these experimental and modeling results indicate that higher and lower frequencies are generated in different paths of the brain hierarchy: while gamma oscillations could be functionally associated with feedforward communication, alpha oscillations could be involved in feedback communication. Combining these findings, if it is true that alpha and gamma rhythms show different and often opposite neurophysiological behavior, it would not be naive to assume that physiological excitation is a key mechanism by which alpha oscillations exert their functional inhibition. In line with this hypothesis, blocking excitation by NMDA antagonists reduces alpha power in humans (Muthukumaraswamy et al., 2015) and monkeys (van Kerkoerle et al., 2014). The hypothetical mechanism by which this physiological excitation inhibits a brain area is, to the best of the author's knowledge, unknown.

\section{Glutamate Receptors Can Shape Alpha Power and Frequency}

Glutamate is the principal excitatory neurotransmitter in the nervous system and it produces EPSPs when binding to NMDA or AMPA receptors. In-vitro and in-vivo animal models speak in favor of the potential role of glutamate in alpha generation. Silva et al. (1991) found that the intrinsic membrane properties of pyramidal neurons in somatosensory cortex layer $\mathrm{V}$ were both necessary and sufficient to fire periodically between 5 and $12 \mathrm{~Hz}$. They showed that $\mathrm{Na}$ and NMDA were essential ingredients to produced synchronized oscillations. More recently, Hughes et al. (2004) convincingly demonstrated that metabotropic glutamate receptor mGluR1a activation in LGN increased the frequency and reduced the amplitude of neuronal oscillations between 2 and $13 \mathrm{~Hz}$. Lörincz et al. (2009) demonstrated "unequivocally that the temporal framing of relay-mode TC neuron activity results from phasic inhibition from LGN interneurons. However, a crucial component in ultimately bringing about this temporal framing is the rhythmic synaptic excitation of interneurons, because without 


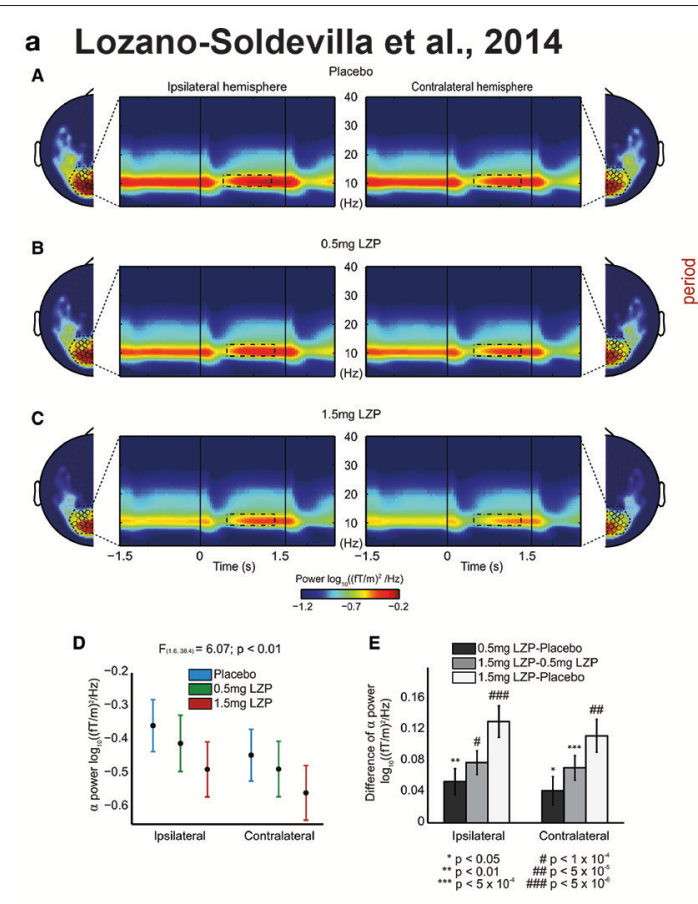

b Himmelstoss et al., 2015

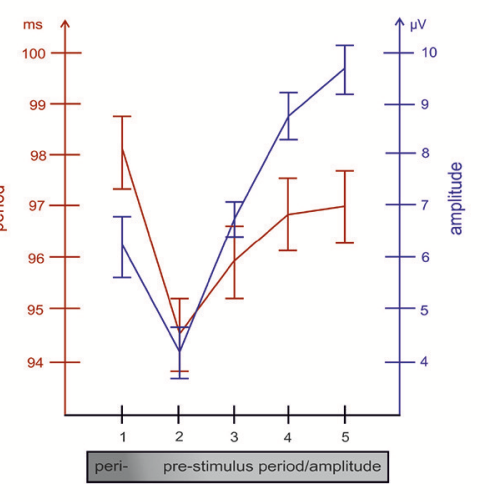

c Bauer et al., 2012

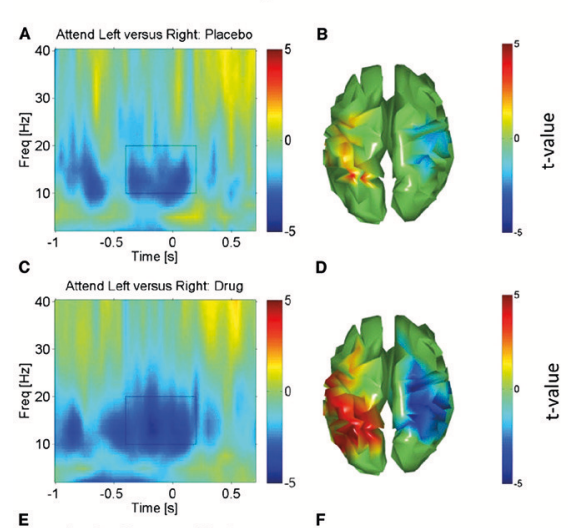

d Carhart-Harris et al., 2016

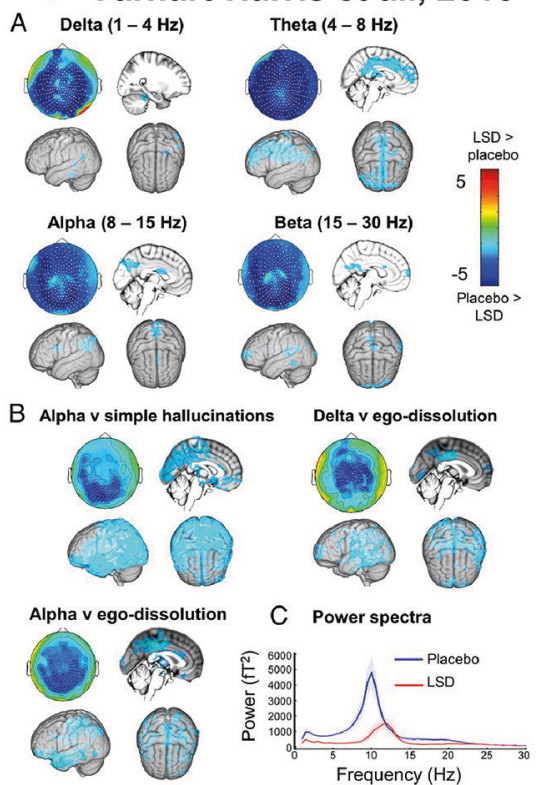

FIGURE 1 | Physiological modulations of parieto-occipital alpha oscillations. (a) Lorazepam (GABAergic enhancer) parametrically reduces both tonic and attentional alpha power modulations during the delay interval of a visuo-spatial working memory task. The figure shows the topographic distribution of alpha power and the time and frequency dynamics of ipsilateral and contralateral sensors of interest under Placebo (A) $0.5 \mathrm{mg}$ (B) and (C) $1.5 \mathrm{mg}$ of Lorazepam. (D,E) show the delay-specific interaction between drug dosage and sensors meaning that Lorazepam caused a strong reduction in the ipsilateral relative to the contralateral sensors. Reproduced from Lozano-Soldevilla et al. (2014) with the permission from Elsevier. (b) Relationship between posterior alpha frequency and EEG amplitude. The x-axis represents the alpha cycles preceding the single trial P1 evoked potential produced in a semantic-judgement task. The left y-axis represents the period of the alpha band (red) and the right $\mathrm{y}$-axis represents the amplitude of the EEG measured at the time point of the positive alpha peak (blue). The EEG raw amplitude correlates positively with alpha frequency. Reproduced from Himmelstoss et al. (2015) with the permission from Frontiers S.A. (c) Physostigmine (cholinergic enhancer) increases the attentional alpha power modulations in parieto-occipital cortices relative to placebo during the cue interval of a visuo-spatial attention task. (A) Time and frequency representation of the left minus right attention contrast during the placebo session of significant parieto-occipital voxels (B). Physostigmine attention contrast and interaction are represented in (C,D) and (E,F), respectively. Reproduced from Bauer et al. (2012) with the permission from Elsevier. (d) LSD (serotonergic enhancer) reduces posterior alpha power during resting state conditions (A). The LSD-induced alpha power reduction correlates with increase of simple hallucination and ego-dissolution ratings (B). LSD produced a robust increase of posterior alpha peak frequency (C). Reproduced from Carhart-Harris et al. (2016) with the permission from Proceedings of the National Academy of Sciences of the United States of America. 
this excitation these cells do not generate action potentials and the phasic inhibition of relay-mode TC neurons does not occur." Finally, a recent ground-breaking monkey study has found that both AMPA and NMDA blockers consistently suppressed alpha power in V1. Interestingly, NMDA blockers, but not AMPA, increased stimulus-induced gamma power within the same brain region and time-period (van Kerkoerle et al., 2014). This pharmacological dissociation was in line with the laminar findings, strengthening the argument that the physiological mechanisms behind alpha and gamma are complementary.

Under resting state conditions, recent pharmaco-MEEG studies found a decrease in parieto-occipital alpha power (Muthukumaraswamy et al., 2015; Rivolta et al., 2015; de la Salle et al., 2016) and frequency (Knott et al., 2006) using subanesthetic doses of ketamine. Surprisingly, the same ketamine and perampanel (AMPA blocker) produced no apparent effecteither in the posterior alpha power, or the frequency in visual stimulation tasks (Shaw et al., 2015; Muthukumaraswamy et al., 2016). Recent studies using ketamine in dosages that induce general anesthesia (loss of consciousness) show similar but stronger alpha modulations (Akeju et al., 2016; Vlisides et al., 2017). All in all, both animal and human experiments agree on the important role of glutamate neurotransmission modulating alpha power and frequency.

\section{Acetylcholine Enhancement Mostly Increases Posterior Alpha Power and Frequency}

Acetylcholine is an organic chemical that can function as both a neurotransmitter and as neuromodulator. It is generated in the pedunculopontine nucleus and in the basal nucleus of Meynert, projecting to various locations in the cortex, hippocampus, and amygdala. Due to its anatomical projections, acetylcholine is a key player during attentive, learning, and memory processes (Thiele, 2013).

It has been reported that while muscarinic blockers like scopolamine diminish the resting parieto-occipital alpha oscillations (Sannita et al., 1987; Sloan et al., 1992; Ebert et al., 1998, 2001; Kikuchi et al., 1999; Osipova et al., 2003; Ramos Reis et al., 2013), nicotinic administration produces the reverse effect (Gilbert et al., 2000; Knott et al., 2000, 2012; Walker et al., 2001; Bowers et al., 2015; Smith et al., 2016) but see (Knott and Fisher, 2007; Balsters et al., 2011; Fisher et al., 2012b). Acetylcholine enhancers tend to increase posterior alpha power during visuospatial attentional modulations (Bauer et al., 2012) Figure 1c and frontal alpha during working memory tasks (Fisher et al., 2012a, 2013) but see (Eckart et al., 2016). Other studies using visual stimulation paradigms reported posterior alpha power increase using mild nicotine dosages (Thompson et al., 2000) while higher dosages caused a decrease (Beaver et al., 2011; Beer et al., 2013). Interestingly, some studies have also found that enhancing cholinergic efficacy leads to a widespread scalp alpha period acceleration (Foulds et al., 1994; Knott et al., 1998, 2006; Domino et al., 2009; Bowers et al., 2015). How can acetylcholine modulate alpha power and frequency? A series of animal models revealed that cholinergic muscarinic receptors $(\mathrm{mAChR})$ play a critical role in inducing intrinsic HT burst-firing in a subset of TC cells (Lörincz et al., 2008). Strikingly, some TC cells with HT bursting activity exhibited a phase-shifting in their spiking output. The phase-shifting varied from a predominantly in-phase relationship with the negative peak of the LFP to an anti-phase relationship. These phase-shifts occurred spontaneously and were determined by a combination of factors such as network input and its intrinsic properties or the polarization of cell-membranes (Lörincz et al., 2008).

\section{Serotonin (5-HT) Can Either Enhance or Suppress Posterior Alpha Power}

The Raphe nuclei is the main serotonin generator responsible for releasing the neurotransmitter to the vast majority of the brain. Regarding its cognitive functions, the prominent innervations between Raphe nuclei and prefrontal cortex suggest a major role in learning, working memory, and cognitive control (Puig and Gulledge, 2011).

A variety of serotonergic enhancers (Venlafaxine, Tianeptine, Ecstasy, Ayahuasca, Psylocibin, LSD) seem to decrease posterior alpha power during both resting (Saletu et al., 1986, 1992; Riba et al., 2002, 2004; Muthukumaraswamy et al., 2013a; Kometer et al., 2015; Schenberg et al., 2015; Carhart-Harris et al., 2016; Valle et al., 2016) but see (Link et al., 1991; Saletu et al., 1996; Knott et al., 2012) and task conditions (Kometer et al., 2013; Muthukumaraswamy et al., 2013a). The serotonergic system has been proposed to play a major role in the generation of visual hallucinations. Substances such as LSD, psilocybin or PCP act on serotonin receptors producing psychotic symptoms (Lieberman et al., 1998). Given the importance of alpha in visual processing, it is not surprising that most of the serotonininduced alpha power modulations are described within the parieto-occipital regions. For example, Kometer et al. (2013) demonstrated a direct link between cortical excitability regulated by parieto-occipital alpha oscillations and visual hallucinations. To unveil the mechanistic role of $5-\mathrm{HT} 2 \mathrm{~A}$ receptors on the ongoing EEG activity, they designed a double-blind cross-over trial where a pre-treatment and a treatment were administered in the same experimental session. Participants were pre-treated with the antagonist ketanserin $(50 \mathrm{mg}$ ) or placebo, and $1 \mathrm{~h}$ later, they could receive either the agonist psilocybin $(215 \mu \mathrm{g} / \mathrm{kg})$ or a placebo. Visual stimulation consisted of three "pacman" figures (300 ms duration) and the participants' task was to press a button as soon as they perceive the classical Kaniza illusion. Perceptually, psilocybin produced robust subjective alterations that were prevented by ketanserin pre-treatment. At the electrophysiological level, they found that psilocybin drastically reduced pre-stimulus alpha power (Kometer et al., 2013). These results support the notion that alpha oscillations regulate cortical excitability by pulsed inhibition, and the levels of alpha power could index visual gain (Klimesch et al., 2007; Mazaheri and Jensen, 2010). Nonetheless, the authors did not find a significant relationship between the drug-induced alpha suppression and the participant's reported intensity of visual hallucinations. 
One of the most idiosyncratic alpha dynamics is its amplitude suppression after stimulus onset (Pfurtscheller and Lopes da Silva, 1999). Kometer et al. also investigated how serotonin upregulation impacted post-stimulus alpha power suppression and the results were very surprising. Psilocybin reduced the alpha power in such a way that there was no further power suppression after the stimulus (Kometer et al., 2013). Control analysis showed that the "absence" of alpha suppression was due to the strong psilocybin effects during pre-stimulus power periods. Importantly, the classical alpha dynamics were recovered using ketanserin as pre-treatment. This is a very important finding that establishes a causal link between alpha stimulus-induced power modulations and serotonin during visual processing. On the same note, the selective $5-\mathrm{HT} 2 \mathrm{~A}$ receptor activation reduced pre-stimulus alpha power to levels very close to "zero" (spectral power is positively-biased so spectral power can never be exactly "zero"). However, in line with (Muthukumaraswamy et al., 2013a), the psilocybin-induced alpha power suppression did not correlate with participants' visual hallucination rates. The lack of significant correlations between subjective scales and psilocybininduced alpha power modulations could be due to floor/ceiling effects on subjective rating measures and/or alpha power levels.

In a very recent multimodal study, participants were scanned with functional magnetic resonance imaging (fMRI) and MEG during resting state conditions under the influence of LSD (Carhart-Harris et al., 2016). The psychedelic drug produced a noteworthy increase of cerebral blood flow over the primary visual cortex (as measured by $\mathrm{fMRI}$ ). During MEG recordings, a robust suppression of parieto-occipital alpha power was found. Importantly, these LSD-induced brain activity changes the predicted quality and intensity of the visual hallucinations (Carhart-Harris et al., 2016). This study also found that LSD produced a remarkable increase in alpha frequency Figure 1d. What might be the functional relevance of this peak frequency change? LSD users often report dramatic visual disturbances or "visual trails" where they perceive a series of discrete stationary images trailing in the wake of otherwise normally moving objects (Dubois and VanRullen, 2011). To estimate the sampling rate of visual trails, Dubois and VanRullen created 10 short movies of 4 frames each, varying the inter-frame interval from 25 to $250 \mathrm{~ms}$. They released the movies on a website and asked selfdeclared past LSD users to decide which movie best matched their recollection of psychedelic experiences. Interestingly, LSD users reported visual trail periodicities around $15-20 \mathrm{~Hz}$ (Dubois and VanRullen, 2011). Although highly speculative, the alpha power suppression and the frequency increase with LSD consumption might produce the segmentation of visual experiences into visual trails, a pharmacologically-induced form of perceptual cycles (VanRullen, 2016). New experiments are needed to test this possibility.

Finally, we still need to understand how serotonin interacts with posterior alpha and the consequences of this interaction for perception and cognition. First, the relationship between perception and alpha is well-documented (VanRullen et al., 2011; Lange et al., 2014). Second, there is growing evidence supporting the firing rate modulation as a function of alpha phase (Bollimunta et al., 2008; Lörincz et al., 2008, 2009; Haegens et al., 2011; Dougherty et al., 2017). Third, animal research has shown that serotonin regulates the power and frequency of neuronal oscillations (Celada et al., 2008; Puig et al., 2010); see (Puig and Gener, 2015) for a review). However, serotonin normalizes cortical excitability in a complex way. It is capable of producing either excitation or inhibition in interneurons and pyramidal cells, and even biphasic responses in the latter (Puig and Gulledge, 2011). How different cell types contribute to alpha oscillations through excitation, inhibition, or its balance and how this modulates behavior remains unknown. New studies are needed to address these issues.

\section{THE NEXT 10 YEARS: COMPUTATIONAL MODELING HOLDS THE KEY TO ADVANCES IN PHARMACO-MEEG}

\begin{abstract}
"The art of modeling is about shaping a model to the questions that motivate it and then making highly educated guesses" (Kopell, 2005).
\end{abstract}

Currently, we live in a research era where neurotechnological innovation is growing exponentially. New invasive recording techniques allow the simultaneous measurement of multiple brain regions, which in turn allow the inquiring of research questions that were impossible to address just a decade ago. However, this unprecedented amount of data acquisition raises serious challenges regarding data management, analysis, and interpretation. And this is where computational models could be crucial: "The overarching goal of theory, modeling and statistics in neuroscience is to create an understanding of how the brain works-how information is encoded and processed by the dynamic activity of specific neural circuits, and how neural coding and processing lead to perception, emotion, cognition and behavior" [...]"Coherent lessons must be drawn not only from the analysis of single experiments, but also by integrating insights across experiments, scales and systems. Theoretical studies will allow us to check the rigor and robustness of new conceptualizations and to identify distinctive predictions of competing ideas to help direct further experiments" (Jorgenson et al., 2015). In line with Kopell's logic, I argue that pharmaco-MEEG needs modeling work in order to improve our mechanistic understanding of how different drugs affect brain activity, and to make highly educated guesses about how drug modulations drive (or hamper) cognition and behavior. In the paragraphs to follow, I briefly present examples of recent modeling work that has provided insights into how different neurotransmitters influence parieto-occipital alpha oscillations.

\section{GABA}

Recent computational models account for the parieto-occipital alpha power decrease produced by GABAergic enhancers. A thalamo-cortical model has suggested two putative neural mechanisms that could explain this remarkable dipole position shift. The model proposes a Hodgkin-Huxley formalism where the frontal alpha power increase (and frequency decrease) can be explained by the effect of GABA imposing a temporal scale 
that entrains thalamo-cortical circuits (Vijayan et al., 2013). Simultaneously, the classical alpha power reduction may be caused by the effect of propofol hyperpolarizing the $h$-current channel on high-threshold (HT) thalamo-cortical cells, which are known to play a key role in the generation of posterior alpha rhythm (Lörincz et al., 2008, 2009). The $h$-current has been shown to be strongly involved in spindle generation (Destexhe and Babloyantz, 1993) but, as discussed earlier, any equivalence between alpha and spindles has to be taken with caution. This model is in line with the findings of an empirical fMRI-EEG study that shows that the pharmacological increase of GABA decreases both thalamic and posterior alpha activity (Schreckenberger et al., 2004).

Other models have highlighted that the interplay between inhibition and excitation might be a key feature of the alpha rhythm. Jones et al. (2000) developed a computational model generating alpha waves by the rebound excitation caused by GABAergic inhibition. They showed that if inhibition is increased pharmacologically, pyramidal cells fire less and alpha power (and frequency) decreases. Years later, Jones et al. (2009) further developed a cortical column model to reproduce the thalamo-cortical sensorimotor mu rhythm. They showed that the somatosensory mu rhythm appeared prominently when the feedforward thalamic input and the cortical feedback were in anti-phase (Jones et al., 2009). In this model, though, increasing GABA conductance in the feedforward $10 \mathrm{~Hz}$ component could lead to an increase of the cortical alpha power, which may explain the inverse relationship between firing rate and power found in some studies (Haegens et al., 2011; van Kerkoerle et al., 2014).

Another approach to modeling brain activity is the one proposed by neural mass models. Instead of modeling the properties of membrane potentials of hundreds of neurons, mass models describe the average activity of an underlying neuronal population (Robinson et al., 2001). The sum of different neuronal populations that can incorporate realistic biophysical parameters can describe macroscopic neural dynamics capable of reproducing and quantifying multiple EEG and MEG phenomena (Bojak and Liley, 2005). For example, (Robinson et al., 2001) modeled a thalamo-cortical loop where populations of excitatory and inhibitory neurons sent their activity to a thalamic population which was connected to the cortex through feedback loops. Hindriks and van Putten (2013) used this model to investigate how GABA modulates the resonance properties of the alpha rhythm. They suggest that the benzodiazepines decrease alpha power because their affinity for $\mathrm{GABA}_{\mathrm{A}}$ receptors situated in pyramidal cells is higher when compared to inhibitory interneurons. The stronger action of GABA on principal cells decreases the firing rate to around $10 \mathrm{~Hz}$, thereby, slowingdown the posterior alpha frequency. Taking recent empirical findings into account, the model is in line with the decrease of posterior alpha power with benzodiazepines, although the frequency modulation is less often reported. This might be due to the low dosages employed across studies.

\section{Acethylcholine and Glutamate}

A recent thalamic conductance-based model reproduced these experimental findings (Vijayan and Kopell, 2012). The model is a network constituted by RE cells, TC cells, HT cells, and interneurons. HT cells provide excitation to interneurons that inhibit TC cells. At the same time, HT and TC cells are connected to RE by AMPA receptors. Furthermore, RE cells inhibits HT cells, TC cells and their own local RE populations by GABAergic inhibition. The model postulates that the phase-shifting depends on mAChR (not on mGluR) and on the burst-firing mode of thalamic inhibitory interneurons. Interneuron single-spike firing favors the in-phase spike-alpha peak relationship and the bursting mode shifts the phase preference by $\pi$ (Vijayan and Kopell, 2012). Moreover, the model makes several testable predictions. Cholinergic activity is very important to control the phasic modulation of the thalamo-cortical alpha rhythm that could lead to perceptual cycles (VanRullen, 2016). Low activation of excitatory mGluR still preserves the mAChRinduced alpha spike-field coherence, whereas strong mGluR activation disrupts it-silencing TC cells by RE and interneurons. Consequently, cortico-thalamic glutamatergic activation could induce an alpha component that prevents a sizable part of thalamic outputs from reaching the cortex. In summary, if the model reflects the machinery behind physiological alpha, mAChR should produce $\sim 10 \mathrm{~Hz}$ oscillations important for stimulus processing while mGluR should generate a different alpha rhythm with a functionally inhibitory role (Vijayan and Kopell, 2012). This model is in line with the speculations I outlined above where alpha oscillations exerting functional inhibition could be implemented by physiological excitation.

\section{5-HT}

Studies like Kometer et al. and Carhart-Harris et al. are amongst the first ones to unveil the neurophysiological mechanisms of visual hallucinations. Still, computational models using plausible biophysical parameters are urgently needed to explain how serotonin modulation produces alpha modulations. Among the exceptions, Muthukumaraswamy et al. (2013a) combined pharmaco-MEG data with dynamic causal modeling (DCM) (Moran et al., 2007) to study the mechanism by which psilocybin desynchronizes posterior cortices. DCM employs neural mass models as generative models to relate specific neural architectures to the EEG. An important advantage of this approach is that one can use Bayesian inversion using the real data to fit a series of mass models with their respective physiological parameters. Muthukumaraswamy et al. (2013a) found that psilocybin produced a robust decrease in alpha power around the parietal cortex during resting state conditions. To describe a potential neural circuit that explains this decrease in energy of the alpha signal, they built a canonical cortical microcircuit represented by neuronal subpopulations of four cell types: spiny stellate, superficial pyramidal, inhibitory interneuron, and deep pyramidal. The neural mass model could reproduce the psilocybin-induced alpha power suppression by the increase in the excitability of deep-layer pyramidal cells (Muthukumaraswamy et al., 2013a). The authors interpreted this finding within the predictive coding framework where the effect of feedback connections is believed to be inhibitory (Bastos et al., 2012). However, a seminal paper showed that feedback connections are not always inhibitory and stimulation within 
the classical or extra-classical receptive field can either excite or inhibit downstream regions (Hupé et al., 1998). It is hoped that future studies will test whether increasing the deep-layer pyramidal activity through serotonin $5-\mathrm{HT} 2{ }_{\mathrm{A}}$ activation yields a suppression of alpha power in posterior cortices.

\section{METHODOLOGICAL CONSIDERATIONS FOR FUTURE STUDIES}

Traditionally, pharmacological studies have been carried out using EEG (Fink, 1969; Niedermeyer and da Silva, 2005), and more recently also MEG (Hall et al., 2010; Muthukumaraswamy, 2014). EEG and MEG measure electric and magnetic fields, respectively, associated to postsynaptic potentials generated by large pools of pyramidal neurons whose activity is coherent in time and space (Niedermeyer and da Silva, 2005). When presynaptic cells release excitatory neurotransmitters such as glutamate, they bind to ionotropic $\alpha$-amino-3-hydroxy-5methyl-4-isoxazolepropionic acid (AMPA) and N-methyl-Daspartate (NMDA) receptors, producing excitatory postsynaptic potentials (EPSP). Conversely, inhibitory postsynaptic potentials (IPSP) are generated by gamma-aminobutyric acid (GABA) inhibitory receptors that hyperpolarize postsynaptic cells. These neurotransmitters mediate excitatory and inhibitory intracellular primary currents (MEG sensitive) which are compensated by balanced extracellular return currents (EEG sensitive). While single neuron action potentials (neural output) produce large currents that are too brief and asynchronous to be temporally integrated, postsynaptic potentials (neural input), in contrast, have a half-life an order of magnitude longer (Timofeev et al., 2012), thereby widening the critical window of temporal integration. In the same vein, spatial integration is archived due to pyramidal cells whose axons are aligned in parallel, producing the so called "open field" configuration (Lorente de Nó, 1947). If a sufficient number of excitatory cells fire in synchrony (temporal integration), the open field configuration (spatial integration) can produce a measurable net potential that extends throughout the conducting medium. In clear contrast, the morphology of inhibitory interneurons is shaped radially, yielding sinks and sources that cancel each other, contributing (in principle) little to EEG and MEG signals (Murakami and Okada, 2006). In sum, the alpha waves recorded with EEG and MEG are mainly driven by spatio-temporally coordinated post-synaptic currents generated by pyramidal cells.

MEG and EEG pharmacological trials involve higher complexity during data acquisition and analysis than standard experiments. In this section, I will highlight two of these challenges and I will suggest possible ways to approach them. For an excellent methodological review about pharmaco-MEG, the reader is referred to Muthukumaraswamy (2014).

\section{The Role of Common Denominator When Comparing Normalized Power Differences}

The binding of pharmacological agents to pyramidal cells and interneurons can produce dramatic changes in EEG and MEG activity. It is thus important to investigate the brain region/s where specific electrophysiological changes seem to be caused by the pharmacological intervention, discarding non-specific changes that covary with the treatment effect but are not related to it. Absolute spectral power estimates are very popular dependent measures routinely reported in pharmacological trials. However, this index can suffer from large variations across experimental sessions, participants, or drug treatments. To facilitate comparisons across studies (or across trials, participants, sessions, etc.) it is highly recommended to employ frequency specific power normalization. Often, this normalization is performed by comparing a specific time window (i.e., post-stimulus) with a baseline period; or, by comparing various task-relevant time windows (i.e., left vs. right allocation of attention). Sometimes drug power or amplitude modulations can be frequency and time specific, that is, only a specific band or time segment can be affected by a drug. For example, Kometer et al. (2013) demonstrated that the impact of psilocybin on alpha power was stronger during the pre-stimulus period, with nonsignificant post-stimulus drug modulations. In these situations, the computation of a relative power change between postand pre-stimulus periods can "move" the significant differences toward the post-stimulus period.

Along the same lines, the use of normalized oscillatory power difference in a pharmaco-MEEG study needs special attention. Alpha modulation index (AMI) and alpha lateralization index (ALI) are very popular metrics to quantify how oscillatory power or amplitude changes as a function of allocation of attention (Thut et al., 2006; Händel et al., 2010). Within the context of a standard spatial attention task, AMI is defined as the alpha power or amplitude difference between the experimental trials where participant's attention is cued to the left and the right experimental conditions: AMI $=$ (Attention Left - Attention Right)./ (Attention Left + Attention Right). In principle, a drug can either increase or decrease the tonic power of the alpha rhythm. Consequently, and under some specific conditions, the denominator of the AMI index can significantly differ between the two treatment conditions (placebo vs. drug). To understand the specific (or general) effects of a drug, it is advisable to compare absolute and relative power or amplitude differences. It may be the case that the numerator of AMI has very similar amplitude or power values for placebo and treatment (although power is the squared amplitude, the rationale of the following example will remain qualitatively the same for both measures). This is indeed the case displayed in Figure 2A: the phasic alpha amplitude modulation (the one associated to the allocation of attention) is almost identical for placebo and drug sessions. If the drug strongly modulates tonic alpha amplitude (increasing or decreasing it), AMI might statistically differ due to tonic amplitude differences (Figure 2B) but not due to an interaction between the treatment and the amplitude modulations caused by participants' allocation of attention. More specifically, Figure 2C clearly shows how the increase in AMI during the drug session (Figure 2B) is explained by the differences in the denominators across treatments and not due to differences in the numerators). The same can happen to ALI, which is defined as the alpha power or amplitude contrast between the two hemispheres for a given spatial attention condition (Thut et al., 2006). To avoid this 


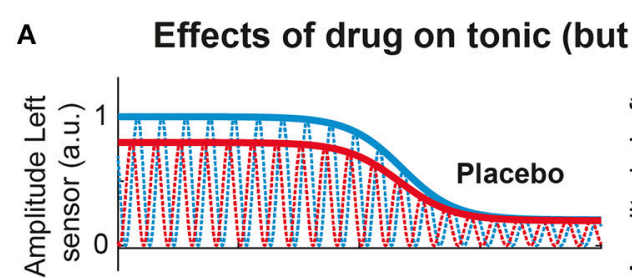

B Effects of normalization on AMI
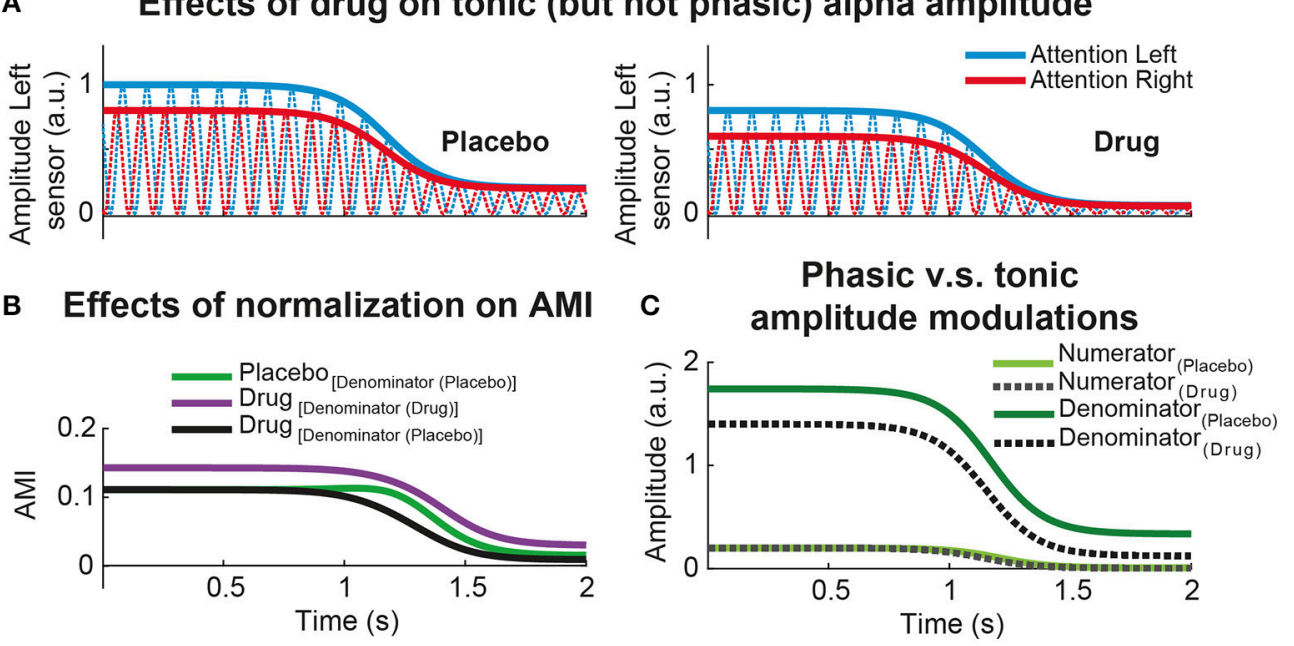

FIGURE 2 | Effect of common denominator when comparing normalized power differences. (A) Simulated alpha power dynamics of a hypothetical MEG sensor from left hemisphere in a visuo-spatial attention task. Red (blue) lines represent the alpha oscillations during attention to the right (left) conditions. The left column illustrated the alpha attentional power modulations during Placebo and the right column during an experimental session where a hypothetical Drug exclusively produces a tonic power reduction ànd leaves the attentional power modulation intact. The power differences between attention to the left (blue) vs. attention to the right conditions (red) is the same for Placebo and Drug. (B) Time-resolved alpha modulation index (AMI) for Placebo and Drug sessions. AMI is defined as the normalized power difference between attentional conditions: (attention to the left - attention to the right)./ (attention to the left + attention to the right). AMl is compared between treatments using different denominator (green vs. purple) or using the same, in this case Placebo (green vs. black). (C) Time-resolved power differences due to attentional (phasic) alpha power modulations (numerator) vs. total (tonic) alpha power (denominator) for each treatment separately. In this simulated example, it is clear that the Drug decreased the total or tonic alpha power (denominator) without interacting with attention (numerator). As the tonic power during Drug is lower relative to Placebo, having the same attentional modulation, the AMl is clearly enhanced using different denominator relative to common denominator (see $\mathbf{B}$ ).

issue, it is recommended to use a common denominator by either taking the mean of alpha power (or amplitude) estimates over treatment conditions, or by using the estimates of the placebo session as a common reference (Figure $2 \mathbf{B}$, black line vs. green line). In this case, it is possible to dissociate the influence of the drug on alpha amplitude modulations due to the allocation of attention (indexed by AMI) and the influence of the drug on tonic alpha amplitude (Figures 2B,C). In the simulated example depicted in Figure 2A, magnitude of the attentional alpha amplitude modulation was almost identical for Placebo and Drug sessions. The Drug, nonetheless, exclusively affected the level of tonic alpha amplitude (Figure 2C, denominator). Importantly, the same rationale can apply to any other type of intervention such as brain stimulation (transcranial and electric stimulation techniques), or when comparing normalized amplitude or power differences extracted from multiple experimental conditions.

\section{Minimizing Head Movements During MEG Experiments}

Head movements during MEG recordings are a common source of noise that the experimenter needs to control as much as possible. In EEG set-ups, the electrodes are attached to the scalp of the participant and small head movements can easily be reduced using chin-rests. In a MEG set-up the problem is the other way around: the participant fits his/her head to the helmet, trying to stay and still as possible. In supine position, it is relatively easy for the participants to remain still. But when sitting down on the MEG chair, head position can drift during the experiment, especially during long sessions ( >30 min). Taking this into account, choosing the supine position is, in principle, a natural choice; but the physiological results may drastically differ relative to sitting position (Rice et al., 2013). Within the context of pharmaco-MEG, participants may move their heads differently during the treatment session due to the side effects of the drugs. Therefore, signal differences between placebo and drug sessions could partially be explained by the difference in head position in the two conditions, thereby limiting the interpretability of the results. It is well-known that dipolar electromagnetic fields decrease at a rate of $1 / \mathrm{r}^{2}$ with the distance of the coil (Hämäläinen et al., 1993), so drifting down on the MEG chair can reduce the amplitude of the MEG signal considerably. In addition, multiple head movements along different directions will contribute to a decrease in the signal-to-noise ratio of the MEG signal. This in turn may eventually diminish the statistical sensitivity of the experimental manipulation at hand. Source reconstruction methods can take into account the distance from participants' head relative to the MEG coils on a trial-by-trial basis, or averaging the head position during the whole experiment (Stolk et al., 2013). Unfortunately, this approach cannot solve all possible caveats. For example, if the head position of a participant lies at the back of the dewar during the first half of the experiment, and then moves a few centimeters to the right (left) or to the front of the dewar, source reconstructions can yield very different results when comparing the first and the second half of the experiment. 
In general, there are two ways to minimize head movement: during the online acquisition of the data and during the postprocessing of the MEG data. The latter procedure employs, for example, an interpolation of the magnetic field distribution produced by the inversion of a forward model generated by taking into account the actual head movements (Knösche, 2002). A different sensor interpolation approach is employed during the signal space separation, where a set of spherical harmonic functions are able to separate the influence of signals originating outside of the MEG coils and, simultaneously, separate artifacts close to the coils (i.e., head movements; Taulu et al., 2005; Medvedovsky et al., 2007). Unfortunately, the MEG signal may be drastically affected when correcting for large head movements (Gross et al., 2013). Taking all these factors into account, it is highly desirable to record head position and to minimize position changes as much as possible during the online acquisition of the experimental data.

A simple and cheap solution is the use of orthopedic neckcollars combined with chair measurements (Lozano-Soldevilla et al., 2014). Especially for MEG experiments involving multiple experimental sessions separated by days, it is very important (and difficult) to seat the participants in the same position. A simple solution consists of taking the height and inclination measurements from the MEG chair for each participant and to reproduce the chair position during subsequent experimental sessions (Figures 3A-D). In addition, soft sponge type neckcollars can easily adapt to most participants while keeping them relatively comfortable. When attached to the neck, one can instruct the volunteers to rest his/her chin on the top of the collar (Figure 3). This action releases the neck muscles from holding the weight of the whole head and reduces fatigue. This approach was especially beneficial because the nature of the drug manipulation in our study. We used benzodiazepine lorazepam in two different dosages to increase GABA efficacy (LozanoSoldevilla et al., 2014). Lorazepam produces loss of muscle tone, so muscles relax and suffer fatigue faster relative to placebo. The use of the collar reduced the fatigue of neck muscle while keeping participants relatively comfortable. That said, besides evidence from their own work, the author is not aware of any empirical measurement demonstrating the superiority of this approach relative to other procedures. However, many researchers carrying out MEG experiments at the Donders Institute have employed them the in the past (Grent-'t-Jong et al., 2013, 2014; Marshall et al., 2016; van de Nieuwenhuijzen et al., 2016), and still continue to employ them (Drijvers et al., 2018) due to good feedback from participants.

A more advanced procedure to monitor and correct head movements was provided by Stolk et al. (2013). They created a real-time head-localizer tool, which is a part of the FieldTrip Matlab toolbox (Oostenveld et al., 2011). For example, in the CTF275 MEG system, head coil positions can be placed at anatomical landmarks (nasion, left and right ear canals) to record head movements. At the beginning of an MEG experiment, head position can be tracked and stored. In case of excessive head movement (i.e., $>5 \mathrm{~mm}$ ), the experimenter can stop the task and instruct the participant to correct his/her head position to recover the original coordinates. Very often, pharmaco-MEG studies employ cross-over designs: the same participant receives placebo and treatment/s in different sessions separated by days. The realtime head-localizer tool allows the experimenter to recover the tracked positions acquired in the very first session so that they can guide the participant to sit as close as possible to the original position (Lozano-Soldevilla et al., 2014).

Finally, it is likely that the future of the MEG and pharmacoMEG research will involve 3D printed head-casts which will drastically improve the online acquisition of data upon the present situation. Initial measurements have revealed impressive results with within- and between-session head movements below 0.25 and $1 \mathrm{~mm}$, respectively (Meyer et al., 2017).

\section{LIMITATIONS}

Psychopharmacological research is essential to monitoring electrophysiological effects of new drugs, and to compare them with well-established treatments. The employment of drugs with well-characterized mechanisms of action can help to develop translational research programs thanks to the priceless knowledge gained in animal models. At the same time, the progress in animal and human psychopharmacological research is very important to constrain computational models with biophysically realistic parameters. These models, once contrasted with empirical data, can help to guide future research proposing mechanistic hypothesis about how specific synaptic receptors generate and/or modulate neuronal oscillations at various frequencies.

However, as with any other approach, pharmaco-MEEG is not exempt from limitations. One of the most important limitations is that pharmacological interventions are system-wide. Moreover, drug agents rarely target one receptor type and will bind to any brain region that contains those specific receptors. It is also challenging to select an optimal drug dosage to produce a measurable behavioral effect not explained by global side effects. Despite the difficulties, there are well-designed studies showing drug-specific effects. For example, Hall et al. (2010) were able to untangle the diazepam-induced resting state neuronal networks into different frequency bands. In a visuospatial attention task, physostigmine strongly enhanced frontal gamma power leaving the stimulus-induced visual gamma "virtually intact" (Bauer et al., 2012). These results point toward a promising future for pharmaco-MEG studies (Hall et al., 2010; Muthukumaraswamy, 2014) and the future development of pharmacological models which test the mechanistic role of neuronal oscillations.

Another important limitation consists of the uncertainty in the ecological validity of the pharmacological model. For example, it has been recently suggested that neuronal oscillations generated with sedative drugs and anesthetics are neurophysiologically different from natural sleep (Akeju and Brown, 2017) despite the striking similarity of some brain states, like the slow waves.

Other main limitation of the pharmacological study of alpha oscillations is that we still do not know the main sources and circuitry of this brain rhythm. Without this knowledge, it is difficult to build in-vitro and computational models (see 

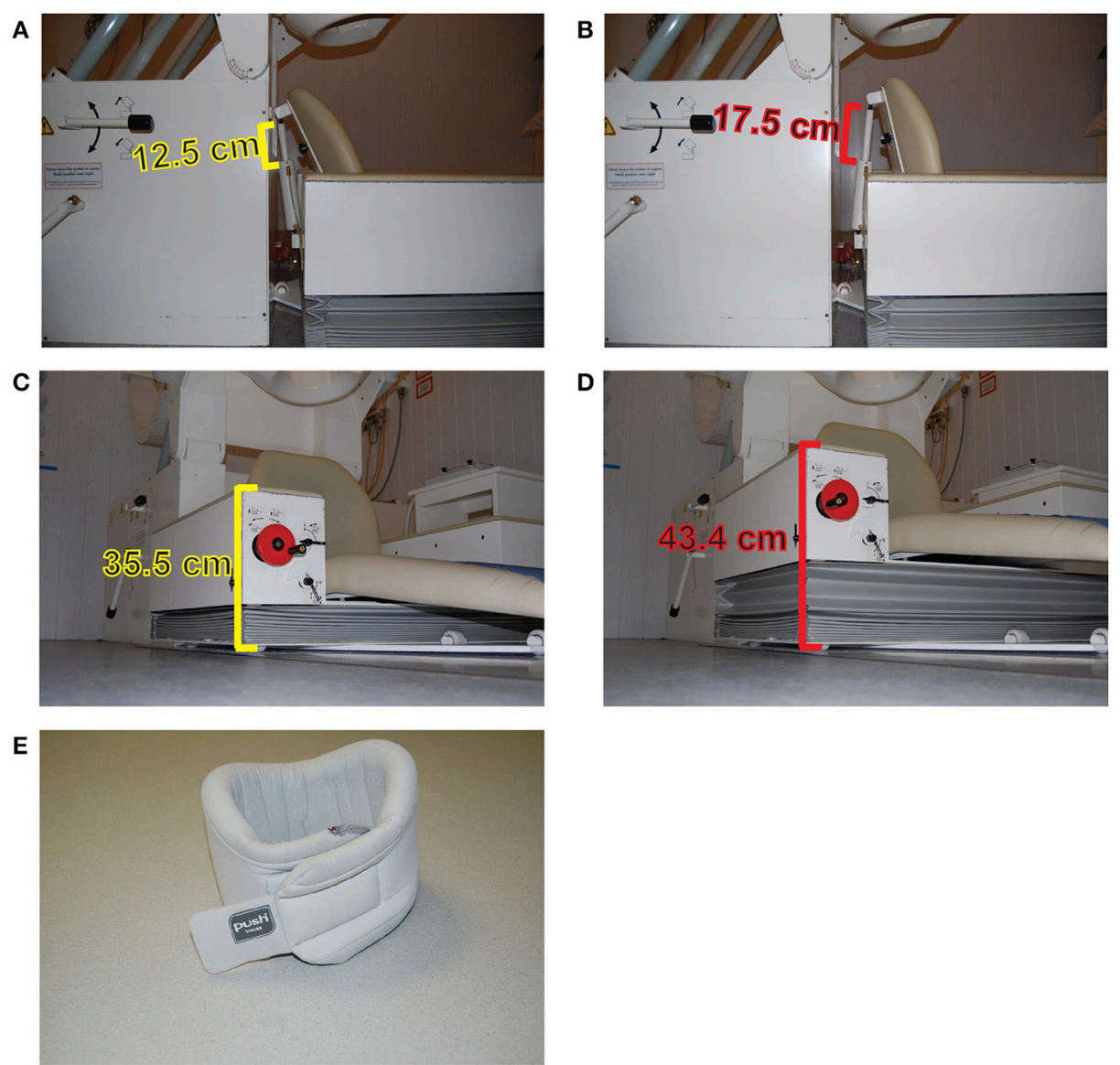

FIGURE 3 | Minimizing head movements during MEG experiments. Measurement of the MEG chair inclination of the CTF275 system in two specific positions (A,B). The height of the chair in two different positions (C,D). Example of a sponge neck-collar (E)

Hughes and Crunelli, 2005 for an exception). The alpha rhythm seems to be a network-based oscillation with multiple local sources interacting each other. In contrast, faster rhythms seem to strongly depend on local circuitry which has facilitated its study in both animal and computational models (Traub et al., 1999). The alpha rhythm can be found over multiple brain regions, even during resting state conditions (Hindriks et al., in review). In addition, using new decomposition techniques, it has recently been found that both attention and performance can be positively and negatively correlated with multiple overlapping alpha and beta sources located over task-relevant and task irrelevant brain regions (van der Meij et al., 2016). This is in line with the disparate pharmacological modulations reviewed here. These two findings reveal that there are multiple alpha components performing complementary roles. How each alpha component is affected by different pharmacological compounds modulating behavior remains to be elucidated. To conclude, these observations are not new and were eloquently described by W. Gray Walter a long time ago:

\footnotetext{
"We've managed to check the alpha band rhythm with intracerebral electrodes in the occipital-parietal cortex; in regions which are practically adjacent and almost congruent one finds a variety of
}

alpha rhythms, some of which are blocked by opening and closing the eyes, some are not, some are driven by flicker, some are not, some respond in some way to mental activity, some do not. What one sees on the scalp is a spatial average of a large number of components, and whether you see an alpha rhythm of a particular type or not depends upon which component happens to be the most highly synchronized process over the largest superficial area; there are complex rhythms in everybody." (Pfurtscheller et al., 1994).

In the future, it will become important to combine computational modeling with pharmacological work to improve the mechanistic understanding of how different receptors contribute to the modulation of posterior alpha oscillations. This knowledge will help the community to develop translational research programs to investigate the pathophysiology of brain rhythms in diseases with well-characterized electrophysiological abnormalities such us epilepsy, Parkinson disease, schizophrenia, or cerebellar ataxia (Traub and Whittington, 2010).

\section{OUTSTANDING QUESTIONS}

The models and experimental findings I have reviewed above provided invaluable insights. Nonetheless, posterior alpha 
oscillations still contain many secrets that future research, hopefully, will unveil:

- It is necessary to continue investigating the sources of parieto-occipital alpha oscillations. While the thalamic mechanisms have been relatively well-studied both empirically (Hughes and Crunelli, 2005; Lörincz et al., 2008, 2009) and computationally (Vijayan and Kopell, 2012), the cortical alpha mechanisms are less clear. To improve the mechanistic understanding of the posterior alpha, in-vitro preparations will be fundamental (Florez et al., 2015) to generating realistic computational models.

- What is the specific contribution of inhibitory interneurons and pyramidal cells to the modulation of alpha frequency and power? Like other inhibitory rhythms such as gamma, can alpha oscillations be exclusively generated by interneurons (Whittington et al., 1995)?

- On a short time scale, alpha frequency is known to fluctuate, and this modulation has been related to the latency of visual P1 (Himmelstoss et al., 2015). In rat hippocampus, it has been shown that instantaneous gamma frequency and power are determined by the tight balance between excitation and inhibition (Atallah and Scanziani, 2009). Is there a similar physiological mechanism to control alpha power and frequency?

- A new impressive study has characterized the beta waves as non-periodic events with a non-sinusoidal waveform caused by the synchrony of excitatory input currents to cortical pyramidal neurons (Sherman et al., 2016). It is well-documented that there is an asymmetry between the magnitude of the peaks and troughs of posterior alpha oscillations (Stam et al., 1999; Nikulin et al., 2007; Mazaheri and Jensen, 2008). Can we extract wave morphology metrics to make inferences underlying the physiology of parieto-occipital alpha oscillations (Cole and Voytek, 2017)? What are the key neurotransmitter(s) and cell types that control alpha waveform and what is its functional relevance (if any)?

- Some studies have shown a relationship between the phase of visual alpha oscillations and neuronal firing (Bollimunta et al., 2008, 2011). Moreover, some studies report the relationship between alpha power and spiking activity as being inverse (Nir et al., 2007; Haegens et al., 2011; van Kerkoerle et al., 2014), some report a positive correlation (Mo et al., 2011; Lakatos et al., 2016), and some studies report no apparent relationship at all (Dougherty et al., 2017). What is the reason for these diverse findings? Is it related to the action of neuromodulators such serotonin or acetylcholine?

- There are only few studies that have found an association between dopamine and posterior alpha oscillations (Chapotot et al., 2003; Eckart et al., 2014) but see (Bodenmann et al., 2009; Albrecht et al., 2016) for negative results. Given the well-established role of dopamine in cognitive control and working memory (Cools and D'Esposito, 2011), and the modulation of posterior alpha power during top-down operations (van Kerkoerle et al., 2014; Bastos et al., 2015; Michalareas et al., 2016), it would be interesting to study how dopamine levels interact with posterior alpha during capacity-limited working memory conditions. Specifically, it has been shown that the relationship between dopamine levels and working memory performance is described by an inverted-U shaped curve. For instance, one could predict that participants with low baseline working memory capacity may increase their performance using dopamine enhancers (Cools and D'Esposito, 2011). It remains to be tested whether posterior alpha desynchronization during the delay interval (Fukuda et al., 2015) interacts with dopamine levels.

- It is still unclear why posterior alpha power dynamics are modulated as a function of working memory contents. Using a Sternberg task employing letters as memoranda, (Jensen et al., 2002) convincingly showed that alpha power during delay interval parametrically increased with memory load. Strikingly, the opposite result is consistently reported using visuospatial working memory tasks (Fukuda et al., 2015). A previous working memory fMRI study demonstrated that physostigmine induced stronger activity in ventral stream relative to dorsal (Handjaras et al., 2013). Could it be that the increase in alpha power in working memory tasks using letters as memoranda is a consequence of the cholinergic neuromodulation of the ventral stream?

\section{CONCLUSION}

In conclusion, recent human pharmacological studies have investigated how the main neurotransmitters and neuromodulators in the central nervous system impact the posterior alpha rhythm. In general, the alpha power was found to decrease with GABAergic enhancers, glutamate blockers and serotonin enhancers, whereas an increase was often reported with acetylcholine. Currently, there is no theoretical framework that can explain these pharmacological findings. Based on these studies, I speculate that the physiological basis of the classical alpha oscillations could depend on physiological excitation to a similar (or stronger) extent as physiological inhibition. Considering the complexity underlying the alpha rhythm, future studies are needed to address how physiological excitation and inhibition contribute to generate the parieto-occipital alpha oscillations. I speculate that a new generation of computational models will be crucial to a mechanistic understanding of alpha oscillations and to reproduce the variety of empirical findings. "How does one draw a conclusion from such a model? It is almost universally believed that with enough parameters in a model, one can reproduce anything. But it is actually the inability to reproduce some details, while trying as hard as possible to be "faithful," that produces the key clues. (The successful use of this methodology requires intense and on-going self-criticism.)" (Kopell, 2005).

\section{AUTHOR CONTRIBUTIONS}

DL-S analyzed data; interpreted results of experiments; prepared figures; drafted manuscript; edited and revised manuscript; approved final version of manuscript. 


\section{ACKNOWLEDGMENTS}

I would like to thank to Frontiers in Computational Neuroscience Editors-in-Chief Profs. Misha Tsodyks, Si Wu, and Idan Segev for their kind invitation to participate in this 10th anniversary

\section{REFERENCES}

Adrian, E. D., and Matthews, B. H. (1934). The Berger rhythm: potential changes from the occipital lobes in man. Brain 57, 355-385. doi: 10.1093/brain/57.4.355 Ahveninen, J., Lin, F. H., Kivisaari, R., Autti, T., Hämäläinen, M., Stufflebeam, S., et al. (2007). MRI-constrained spectral imaging of benzodiazepine modulation of spontaneous neuromagnetic activity in human cortex. Neuroimage 35, 577-582. doi: 10.1016/j.neuroimage.2006.12.033

Akeju, O., and Brown, E. N. (2017). Neural oscillations demonstrate that general anesthesia and sedative states are neurophysiologically distinct from sleep. Curr. Opin. Neurobiol. 44, 178-185. doi: 10.1016/j.conb.2017.04.011

Akeju, O., Song, A. H., Hamilos, A. E., Pavone, K. J., Flores, F. J., Brown, E. N., et al. (2016). Electroencephalogram signatures of ketamine anesthesia-induced unconsciousness. Clin. Neurophysiol. 127, 2414-2422. doi: 10.1016/j.clinph.2016.03.005

Albe-Fessard, D. (1973). Electrophysiological methods for the identification of thalamic nuclei. Z. Neurol. 205, 15-28. doi: 10.1007/BF00315957

Albe-Fessard, D., Arfel, G., Guiot, G., Derome, P., Hertzog, E., Vourc'h, G., et al. (1966). Electrophysiological studies of some deep cerebral structures in man. J. Neurol. Sci. 3, 37-51. doi: 10.1016/0022-510X(66)90038-4

Albrecht, M. A., Roberts, G., Price, G., Lee, J., Iyyalol, R., and MartinIverson, M. T. (2016). The effects of dexamphetamine on the resting-state electroencephalogram and functional connectivity. Hum. Brain Mapp. 37, 570-588. doi: 10.1002/hbm.23052

Alonso, J. F., Romero, S., Mañanas, M. Á., Rojas, M., Riba, J., and Barbanoj, M. J. (2015). Evaluation of multiple comparison correction procedures in drug assessment studies using LORETA maps. Med. Biol. Eng. Comput. 53, 1011-1023. doi: 10.1007/s11517-015-1315-6

Andersen, P., and Andersson, S. A. (1968). Physiological Basis of the Alpha Rhythm. New York, NY: Appelton Century Crofts.

Anderson, J. S., Carandini, M., and Ferster, D. (2000). Orientation tuning of input conductance, excitation, and inhibition in cat primary visual cortex. $J$. Neurophysiol. 84, 909-926. doi: 10.1152/jn.2000.84.2.909

Antkowiak, B. (1999). Different actions of general anesthetics on the firing patterns of neocortical neurons mediated by the GABAA receptor. Anesthesiology 91, 500-511. doi: 10.1097/00000542-199908000-00025

Atallah, B. V., and Scanziani, M. (2009). Instantaneous modulation of gamma oscillation frequency by balancing excitation with inhibition. Neuron 62, 566-577. doi: 10.1016/j.neuron.2009.04.027

Bai, D., Pennefather, P. S., MacDonald, J. F., and Orser, B. A. (1999). The general anesthetic propofol slows deactivation and desensitization of $\mathrm{GABA}_{\mathrm{A}}$ receptors. J. Neurosci. 19, 10635-10646.

Balsters, J. H., O’Connell, R. G., Martin, M. P., Galli, A., Cassidy, S. M., Kilcullen, S. M., et al. (2011). Donepezil impairs memory in healthy older subjects: behavioural, EEG and simultaneous EEG/fMRI biomarkers. PLoS ONE 6:e24126. doi: 10.1371/journal.pone.0024126

Bastos, A. M., Vezoli, J., Bosman, C. A., Schoffelen, J.-M., Oostenveld, R., Dowdall, J. R., et al. (2015). Visual areas exert feedforward and feedback influences through distinct frequency channels. Neuron 85, 390-401. doi: 10.1016/j.neuron.2014.12.018

Bastos, A. M., Usrey, W. M., Adams, R. A., Mangun, G. R., Fries, P., and Friston, K. J. (2012). Canonical microcircuits for predictive coding. Neuron 76, 695-711. doi: 10.1016/j.neuron.2012.10.038

Bauer, M., Kluge, C., Bach, D., Bradbury, D., Heinze, H. J., Dolan, R. J., et al. (2012). Cholinergic enhancement of visual attention and neural oscillations in the human brain. Curr. Biol. 22, 397-402. doi: 10.1016/j.cub.2012.01.022

Beaver, J. D., Long, C. J., Cole, D. M., Durcan, M. J., Bannon, L. C., Mishra, R. G., et al. (2011). The effects of nicotine replacement on cognitive brain
Research Topic. I am thankful to Prof. Wolfgang Klimesch and Dra. Stephanie R. Jones for their insightful discussions regarding the relationship between GABA and alpha. I am indebted to Dr. Tushar Chauhan for his helpful comments and proofreading. activity during smoking withdrawal studied with simultaneous fMRI/EEG. Neuropsychopharmacology 36, 1792-1800. doi: 10.1038/npp.2011.53

Beer, A. L., Vartak, D., and Greenlee, M. W. (2013). Nicotine facilitates memory consolidation in perceptual learning. Neuropharmacology 64, 443-451. doi: 10.1016/j.neuropharm.2012.06.019

Berger, H. (1929). Über das elektrenkephalogramm des menschen. Arch. Psychiatr. Nervenkr. 87, 527-570. doi: 10.1007/BF01797193

Bodenmann, S., Rusterholz, T., Dürr, R., Stoll, C., Bachmann, V., Geissler, E., et al. (2009). The functional Val158Met polymorphism of COMT predicts interindividual differences in brain $\alpha$ oscillations in young men. J. Neurosci. 29, 10855-10862. doi: 10.1523/JNEUROSCI.1427-09.2009

Boeijinga, P. H., Parot, P., Soufflet, L., Landron, F., Danel, T., Gendre, I., et al. (2004). Pharmacodynamic effects of acamprosate on markers of cerebral function in alcohol-dependent subjects administered as pretreatment and during alcohol abstinence. Neuropsychobiology 50, 71-77. doi: $10.1159 / 000077944$

Bojak, I., and Liley, D. T. (2005). Modeling the effects of anesthesia on the electroencephalogram. Phys. Rev.E 71:041902. doi: 10.1103/PhysRevE.71.041902

Bollimunta, A., Chen, Y., Schroeder, C. E., and Ding, M. (2008). Neuronal mechanisms of cortical alpha oscillations in awake-behaving macaques. J. Neurosci. 28, 9976-9988. doi: 10.1523/JNEUROSCI.269908.2008

Bollimunta, A., Mo, J., Schroeder, C. E., and Ding, M. (2011). Neuronal mechanisms and attentional modulation of corticothalamic alpha oscillations. J. Neurosci. 31, 4935-4943. doi: 10.1523/JNEUROSCI.5580-10.2011

Bond, A., and Lader, M. (1982). A comparison of the psychotropic profiles of tofisopam and diazepam. Eur. J. Clin. Pharmacol. 22, 137-142. doi: 10.1007/BF00542458

Bowers, H., Smith, D., de la Salle, S., Choueiry, J., Impey, D., Philippe, T., et al. (2015). COMT polymorphism modulates the resting-state EEG alpha oscillatory response to acute nicotine in male non-smokers. Genes Brain Behav. 14, 466-476. doi: 10.1111/gbb.12226

Buehlmann, A., and Deco, G. (2008). The neuronal basis of attention: rate versus synchronization modulation. J. Neurosci. 28, 7679-7686. doi: 10.1523/JNEUROSCI.5640-07.2008

Buffalo, E. A., Fries, P., Landman, R., Buschman, T. J., and Desimone, R. (2011). Laminar differences in gamma and alpha coherence in the ventral stream. Proc. Natl. Acad. Sci. U.S.A. 108, 11262-11267. doi: 10.1073/pnas.1011284108

Campbell, A. E., Sumner, P., Singh, K. D., and Muthukumaraswamy, S. D. (2014). Acute Effects of Alcohol on Stimulus-Induced Gamma Oscillations in Human Primary Visual and Motor Cortices. Neuropsychopharmacology 39, 2104-2113. doi: $10.1038 /$ npp. 2014.58

Carhart-Harris, R. L., Muthukumaraswamy, S., Roseman, L., Kaelen, M., Droog, W., Murphy, K., et al. (2016). Neural correlates of the LSD experience revealed by multimodal neuroimaging. Proc. Natl. Acad. Sci. U.S.A. 113, 4853-4858. doi: $10.1073 /$ pnas. 1518377113

Castro-Alamancos, M. A., and Connors, B. W. (1996). Cellular Mechanisms of the augmenting response: short-term plasticity in a thalamocortical pathway. J. Neurosci. 16, 7742-7756

Celada, P., Puig, M. V., Díaz-Mataix, L., and Artigas, F. (2008). The hallucinogen DOI reduces low-frequency oscillations in rat prefrontal cortex: reversal by antipsychotic drugs. Biol. Psychiatry 64, 392-400. doi: 10.1016/j.biopsych.2008.03.013

Chapotot, F., Pigeau, R., Canini, F., Bourdon, L., and Buguet, A. (2003). Distinctive effects of modafinil and d-amphetamine on the homeostatic and circadian modulation of the human waking EEG. Psychopharmacology 166, 127-138. doi: $10.1007 / \mathrm{s} 00213-002-1315-8$ 
Ching, S., Cimenser, A., Purdon, P. L., Brown, E. N., and Kopell, N. J. (2010). Thalamocortical model for a propofol-induced $\alpha$-rhythm associated with loss of consciousness. Proc. Natl. Acad. Sci. U.S.A. 107, 22665-22670. doi: 10.1073/pnas.1017069108

Cimenser, A., Purdon, P. L., Pierce, E. T., Walsh, J. L., Salazar-Gomez, A. F., Harrell, P. G., et al. (2011). Tracking brain states under general anesthesia by using global coherence analysis. Proc. Natl. Acad. Sci. U.S.A. 108, 8832-8837. doi: $10.1073 /$ pnas. 1017041108

Cole, S. R., and Voytek, B. (2017). Brain oscillations and the importance of waveform shape. Trends Cogn. Sci. 21, 137-149. doi: 10.1016/j.tics.2016.12.008

Connemann, B. J., Mann, K., Lange-Asschenfeldt, C., Ruchsow, M., Schreckenberger, M., Bartenstein, P., et al. (2005). Anterior limbic alpha-like activity: a low resolution electromagnetic tomography study with lorazepam challenge. Clin. Neurophysiol. 116, 886-894. doi: 10.1016/j.clinph.2004.11.015

Cools, R., and D'Esposito, M. (2011). Inverted-U shaped dopamine actions on human working memory and cognitive control. Biol. Psychiatry 69, e113-e125. doi: 10.1016/j.biopsych.2011.03.028

de la Salle, S., Choueiry, J., Shah, D., Bowers, H., McIntosh, J., Ilivitsky, V., et al. (2016). Effects of ketamine on resting-state EEG activity and their relationship to perceptual/dissociative symptoms in healthy humans. Front. Pharmacol. 7:348. doi: $10.3389 /$ fphar.2016.00348

Deco, G., and Thiele, A. (2009). Attention - oscillations and neuropharmacology. Eur. J. Neurosci. 30, 347-354. doi: 10.1111/j.1460-9568.2009.06833.x

Destexhe, A., and Babloyantz, A. (1993). A model of the inward current Ih and its possible role in thalamocortical oscillations. Neuroreport 4, 223. doi: 10.1097/00001756-199302000-00028

Domino, E. F., Ni, L., Thompson, M., Zhang, H., Shikata, H., Fukai, H., et al. (2009). Tobacco smoking produces widespread dominant brain wave alpha frequency increases. Int. J. Psychophysiol. 74, 192-198. doi: 10.1016/j.ijpsycho.2009.08.011

Dougherty, K., Cox, M. A., Ninomiya, T., Leopold, D. A., and Maier, A. (2017). Ongoing alpha activity in V1 regulates visually driven spiking responses. Cereb. Cortex 27, 1113-1124. doi: 10.1093/cercor/bhv304

Drijvers, L., Özyürek, A., and Jensen, O. (2018). Hearing and seeing meaning in noise: alpha, beta, and gamma oscillations predict gestural enhancement of degraded speech comprehension. Hum. Brain Mapp. doi: 10.1002/hbm. 23987. [Epub ahead of print].

Dubois, J., and VanRullen, R. (2011). Visual trails: do the doors of perception open periodically? PLoS Biol. 9:e1001056. doi: 10.1371/journal.pbio.1001056

Ebert, U., Grossmann, M., Oertel, R., Gramatté, T., and Kirch, W. (2001). Pharmacokinetic-pharmacodynamic modeling of the electroencephalogram effects of scopolamine in healthy volunteers. J. Clin. Pharmacol. 41, 51-60. doi: $10.1177 / 00912700122009836$

Ebert, U., Oertel, R., Wesnes, K. A., and Kirch, W. (1998). Effects of physostigmine on scopolamine-induced changes in quantitative electroencephalogram and cognitive performance. Hum. Psychopharm. Clin. 13, 199-210. doi: 10.1002/(SICI)1099-1077(199804)13:3<199::AID-HUP974>3.0.CO;2-3

Eckart, C., Fuentemilla, L., Bauch, E. M., and Bunzeck, N. (2014). Dopaminergic stimulation facilitates working memory and differentially affects prefrontal low theta oscillations. Neuroimage 94, 185-192. doi: 10.1016/j.neuroimage.2014.03.011

Eckart, C., Wozniak-Kwaśniewska, A., Herweg, N. A., Fuentemilla, L., and Bunzeck, N. (2016). Acetylcholine modulates human working memory and subsequent familiarity based recognition via alpha oscillations. Neuroimage 137, 61-69. doi: 10.1016/j.neuroimage.2016.05.049

Fanselow, E. E., and Nicolelis, M. A. (1999). Behavioral modulation of tactile responses in the rat somatosensory system. J. Neurosci. 19, 7603-7616.

Feshchenko, V. A., Veselis, R. A., and Reinsel, R. A. (1997). Comparison of the EEG effects of midazolam, thiopental, and propofol: the role of underlying oscillatory systems. Neuropsychobiology 35, 211-220. doi: 10.1159/000 119347

Feshchenko, V. A., Veselis, R. A., and Reinsel, R.A. (2004). Propofol-induced alpha rhythm. Neuropsychobiology 50, 257-266. doi: 10.1159/000079981

Fingelkurts, A. A., Fingelkurts, A. A., Kivisaari, R., Pekkonen, E., Ilmoniemi, R. J., and Kähkönen, S. (2004). The interplay of lorazepam-induced brain oscillations: microstructural electromagnetic study. Clin. Neurophysiol. 115, 674-690. doi: 10.1016/j.clinph.2003.10.025
Fink, M. (1969). EEG and human psychopharmacology. Annu. Rev. Pharmacol. 9, 241-258. doi: 10.1146/annurev.pa.09.040169.001325

Fink, M., Weinfeld, R. E., Schwartz, M. A., and Conney, A. H. (1976). Blood levels and electroencephalographic effects of diazepam and bromazepam. Clin. Pharmacol. Ther. 20, 184-191. doi: 10.1002/cpt1976202184

Fisher, D. J., Daniels, R., Jaworska, N., Knobelsdorf, A., and Knott, V. J. (2012a). Effects of acute nicotine administration on behavioral and neural (EEG) correlates of working memory in non-smokers. Brain Res. 1429, 72-81. doi: 10.1016/j.brainres.2011.10.029

Fisher, D. J., Daniels, R., Jaworska, N., Knobelsdorf, A., and Knott, V. J. (2012b). Effects of acute nicotine administration on resting EEG in nonsmokers. Exp. Clin. Psychopharmacol. 20, 71-75. doi: 10.1037/a0025221

Fisher, D. J., Knobelsdorf, A., Jaworska, N., Daniels, R., and Knott, V. J. (2013). Effects of nicotine on electroencephalographic (EEG) and behavioural measures of visual working memory in non-smokers during a dual-task paradigm. Pharmacol. Biochem. Behav. 103, 494-500. doi: 10.1016/j.pbb.2012.09.014

Flint, A. C., and Connors, B. W. (1996). Two types of network oscillations in neocortex mediated by distinct glutamate receptor subtypes and neuronal populations. J. Neurophysiol. 75, 951-957. doi: 10.1152/jn.1996.75.2.951

Florez, C. M., McGinn, R. J., Lukankin, V., Marwa, I., Sugumar, S., Dian, J., et al. (2015). In vitro recordings of human neocortical oscillations. Cereb. Cortex 25, 578-597. doi: 10.1093/cercor/bht235

Foulds, J., McSorley, K., Sneddon, J., Feyerabend, C., Jarvis, M. J., and Russell, M. A. (1994). Effect of subcutaneous nicotine injections on EEG alpha frequency in non-smokers: a placebo-controlled pilot study. Psychopharmacology 115, 163-166. doi: 10.1007/BF02244767

Foxe, J. J., Simpson, G. V., and Ahlfors, S. P. (1998). Parieto-occipital $\sim 10 \mathrm{~Hz}$ activity reflects anticipatory state of visual attention mechanisms. Neuroreport 9, 3929-3933. doi: 10.1097/00001756-199812010-00030

Foxe, J. J., and Snyder, A. C. (2011). The role of alpha-band brain oscillations as a sensory suppression mechanism during selective attention. Front. Psychol. 2:154. doi: $10.3389 /$ fpsyg.2011.00154

Fries, P. (2015). Rhythms for cognition: communication through coherence. Neuron 88, 220-235. doi: 10.1016/j.neuron.2015.09.034

Fries, P., Reynolds, J. H., Rorie, A. E., and Desimone, R. (2001). Modulation of oscillatory neuronal synchronization by selective visual attention. Science 291, 1560-1563.doi: 10.1126/science.291.5508.1560

Fukuda, K., Mance, I., and Vogel, E. K. (2015). a power modulation and eventrelated slow wave provide dissociable correlates of visual working memory. $J$. Neurosci. 35, 14009-14016. doi: 10.1523/JNEUROSCI.5003-14.2015

Gevins, A., Smith, M. E., and McEvoy, L. K. (2002). Tracking the cognitive pharmacodynamics of psychoactive substances with combinations of behavioral and neurophysiological measures. Neuropsychopharmacology 26, 27-39. doi: 10.1016/S0893-133X(01)00300-1

Gilbert, D. G., Dibb, W. D., Plath, L. C., and Hiyane, S. G. (2000). Effects of nicotine and caffeine, separately and in combination, on EEG topography, mood, heart rate, cortisol, and vigilance. Psychophysiology 37, 583-595. doi: 10.1111/1469-8986.3750583

Gips, B., van der Eerden, J. P., and Jensen, O. (2016). A biologically plausible mechanism for neuronal coding organized by the phase of alpha oscillations. Eur. J. Neurosci. 44, 2147-2161. doi: 10.1111/ejn.13318

Golombok, S., and Lader, M. (1984). The psychopharmacological effects of premazepam, diazepam and placebo in healthy human subjects. Br. J. Clin. Pharmacol. 18, 127-133. doi: 10.1111/j.1365-2125.1984.tb02444.x

Grent-'t-Jong, T., Oostenveld, R., Jensen, O., Medendorp, W. P., and Praamstra, P. (2014). Competitive interactions in sensorimotor cortex: oscillations express separation between alternative movement targets. J. Neurophysiol. 112, 224-232. doi: 10.1152/jn.00127.2014

Grent-'t-Jong, T., Oostenveld, R., Jensen, O., Medendorp, W. P., and Praamstra, P. (2013). Oscillatory dynamics of response competition in human sensorimotor cortex. Neuroimage 83, 27-34. doi: 10.1016/j.neuroimage.2013.06.051

Gross, J., Baillet, S., Barnes, G. R., Henson, R. N., Hillebrand, A., Jensen, O., et al. (2013). Good practice for conducting and reporting MEG research. Neuroimage 65, 349-363. doi: 10.1016/j.neuroimage.2012.10.001

Gücer, G., Niedermeyer, E., and Long, D. M. (1978). Thalamic EEG recordings in patients with chronic pain. J. Neurol. 219, 47-61. doi: 10.1007/BF00313368 
Haegens, S., Barczak, A., Musacchia, G., Lipton, M. L., Mehta, A. D., Lakatos, P., et al. (2015). Laminar profile and physiology of the $\alpha$ rhythm in primary visual, auditory, and somatosensory regions of neocortex. J. Neurosci. 35, 14341-14352. doi: 10.1523/JNEUROSCI.0600-15.2015

Haegens, S., Nácher, V., Luna, R., Romo, R., and Jensen, O. (2011). $\alpha$-Oscillations in the monkey sensorimotor network influence discrimination performance by rhythmical inhibition of neuronal spiking. Proc. Natl. Acad. Sci. U.S.A. 108, 19377-19382. doi: 10.1073/pnas.1117190108

Hall, S. D., Barnes, G. R., Furlong, P. L., Seri, S., and Hillebrand, A. (2010). Neuronal network pharmacodynamics of GABAergic modulation in the human cortex determined using pharmaco-magnetoencephalography. Hum. Brain Mapp. 31, 581-594. doi: 10.1002/hbm.20889

Hämäläinen, M., Hari, R., Ilmoniemi, R. J., Knuutila, J., and Lounasmaa, O. V. (1993). Magnetoencephalography - theory, instrumentation, and applications to noninvasive studies of the working human brain. Rev. Mod. Phys. 65, 413-497. doi: 10.1103/RevModPhys.65.413

Händel, B. F., Haarmeier, T., and Jensen, O. (2010). Alpha oscillations correlate with the successful inhibition of unattended stimuli. J. Cogn. Neurosci. 23, 2494-2502. doi: 10.1162/jocn.2010.21557

Handjaras, G., Ricciardi, E., Szczepanik, J., Pietrini, P., and Furey, M. L. (2013). Cholinergic enhancement differentially modulates neural response to encoding during face identity and face location working memory tasks. Exp. Biol. Med. 238, 999-1008. doi: 10.1177/1535370213497326

Himmelstoss, N. A., Brötzner, C. P., Zauner, A., Kerschbaum, H. H., Gruber, W., Lechinger, J., et al. (2015). Prestimulus amplitudes modulate P1 latencies and evoked traveling alpha waves. Front. Hum. Neurosci. 9:302. doi: 10.3389/fnhum.2015.00302

Hindriks, R., and van Putten, M. J. (2013). Thalamo-cortical mechanisms underlying changes in amplitude and frequency of human alpha oscillations. Neuroimage 70, 150-163. doi: 10.1016/j.neuroimage.2012.12.018

Hoogenboom, N., Schoffelen, J.-M., Oostenveld, R., Parkes, L. M., and Fries, P. (2006). Localizing human visual gamma-band activity in frequency, time and space. Neuroimage 29, 764-773. doi: 10.1016/j.neuroimage.2005.08.043

Hughes, S. W., and Crunelli, V. (2005). Thalamic mechanisms of EEG alpha rhythms and their pathological implications. Neuroscientist 11, 357-372. doi: $10.1177 / 1073858405277450$

Hughes, S. W., Lörincz, M., Cope, D. W., Blethyn, K. L., Kékesi, K. A., Parri, H. R., et al. (2004). Synchronized oscillations at $\alpha$ and $\theta$ frequencies in the lateral geniculate nucleus. Neuron 42, 253-268. doi: 10.1016/S0896-6273(04)00191-6

Hughes, S. W., Lorincz, M. L., Turmaine, M., and Crunelli, V. (2011). Thalamic gap junctions control local neuronal synchrony and influence macroscopic oscillation amplitude during EEG alpha rhythms. Front. Psychol. 2:193. doi: $10.3389 /$ fpsyg.2011.00193

Hupé, J. M., James, A. C., Payne, B. R., Lomber, S. G., Girard, P., and Bullier, J. (1998). Cortical feedback improves discrimination between figure and background by V1, V2 and V3 neurons. Nature 394, 784-787.

Jensen, O., and Mazaheri, A. (2010). Shaping functional architecture by oscillatory alpha activity: gating by inhibition. Front. Hum. Neurosci. 5:186. doi: 10.3389/fnhum.2010.00186

Jensen, O., Bonnefond, M., and VanRullen, R. (2012). An oscillatory mechanism for prioritizing salient unattended stimuli. Trends Cogn. Sci. 16, 200-206. doi: $10.1016 /$ j.tics.2012.03.002

Jensen, O., Gelfand, J., Kounios, J., and Lisman, J. E. (2002). Oscillations in the alpha band $(9-12 \mathrm{~Hz})$ increase with memory load during retention in a shortterm memory task. Cereb. Cortex 12, 877-882. doi: 10.1093/cercor/12.8.877

Jensen, O., Gips, B., Bergmann, T. O., and Bonnefond, M. (2014). Temporal coding organized by coupled alpha and gamma oscillations prioritize visual processing. Trends Neurosci. 37, 357-369. doi: 10.1016/j.tins.2014.04.001

Jensen, O., Goel, P., Kopell, N., Pohja, M., Hari, R., and Ermentrout, B. (2005). On the human sensorimotor-cortex beta rhythm: sources and modeling. Neuroimage 26, 347-355. doi: 10.1016/j.neuroimage.2005.02.008

Jones, S. R., Pritchett, D. L., Sikora, M. A., Stufflebeam, S. M., Hämäläinen, M., and Moore, C. I. (2009). Quantitative analysis and biophysically realistic neural modeling of the MEG Mu rhythm: rhythmogenesis and modulation of sensoryevoked responses. J. Neurophysiol. 102, 3554-3572. doi: 10.1152/jn.00535.2009

Jones, S. R., Pinto, D. J., Kaper, T. J., and Kopell, N. (2000). Alpha-frequency rhythms desynchronize over long cortical distances: a modeling study. J. Comput. Neurosci. 9, 271-291. doi: 10.1023/A:1026539805445
Jorgenson, L. A., Newsome, W. T., Anderson, D. J., Bargmann, C. I., Brown, E. N., Deisseroth, K., et al. (2015). The BRAIN Initiative: developing technology to catalyse neuroscience discovery. Philos. Trans. R. Soc. Lond. B Biol. Sci. 370:20140164. doi: 10.1098/rstb.2014.0164

Kikuchi, M., Wada, Y., Nanbu, Y., Nakajima, A., Tachibana, H., Takeda, T., et al. (1999). EEG changes following scopolamine administration in healthy subjects. Quantitative analysis during rest and photic stimulation. Neuropsychobiology 39, 219-226. doi: 10.1159/000026588

Klimesch, W. (2012). Alpha-band oscillations, attention, and controlled access to stored information. Trends Cogn. Sci. 16, 606-617. doi: 10.1016/j.tics.2012.10.007

Klimesch, W., Sauseng, P., and Hanslmayr, S. (2007). EEG alpha oscillations: the inhibition-timing hypothesis. Brain Res. Rev. 53, 63-88. doi: 10.1016/j.brainresrev.2006.06.003

Knösche, T. (2002). Transformation of whole-head MEG recordings between different sensor positions. Biomed. Tech. 47, 59-62. doi: $10.1515 /$ bmte.2002.47.3.59

Knott, V. J., and Fisher, D. J. (2007). Naltrexone alteration of the nicotine-induced EEG and mood activation response in tobacco-deprived cigarette smokers. Exp. Clin. Psychopharmacol. 15, 368-381. doi: 10.1037/1064-1297.15.4.368

Knott, V. J., Harr, A., Ilivitsky, V., and Mahoney, C. (1998). The cholinergic basis of the smoking-induced EEG activation profile. Neuropsychobiology 38, 97-107. doi: $10.1159 / 000026524$

Knott, V., Engeland, C., Mohr, E., Mahoney, C., and Ilivitsky, V. (2000). Acute nicotine administration in Alzheimer's disease: an exploratory EEG study. Neuropsychobiology 41, 210-220. doi: 10.1159/000026662

Knott, V., McIntosh, J., Millar, A., Fisher, D., Villeneuve, C., Ilivitsky, V., et al. (2006). Nicotine and smoker status moderate brain electric and mood activation induced by ketamine, an N-methyl-d-aspartate (NMDA) receptor antagonist. Pharmacol. Biochem. Behav. 85, 228-242. doi: 10.1016/j.pbb.2006.08.005

Knott, V., Thompson, A., Shah, D., and Ilivitsky, V. (2012). Neural expression of nicotine's antidepressant properties during tryptophan depletion: an EEG study in healthy volunteers at risk for depression. Biol. Psychol. 91, 190-200. doi: 10.1016/j.biopsycho.2012.06.002

Kometer, M., Pokorny, T., Seifritz, E., and Volleinweider, F. X. (2015). Psilocybin-induced spiritual experiences and insightfulness are associated with synchronization of neuronal oscillations. Psychopharmacology 232, 3663-3676. doi: 10.1007/s00213-015-4026-7

Kometer, M., Schmidt, A., Jäncke, L., and Vollenweider, F. X. (2013). Activation of serotonin $2 \mathrm{~A}$ receptors underlies the psilocybin-induced effects on $\alpha$ oscillations, N170 visual-evoked potentials, and visual hallucinations. J. Neurosci. 33, 10544-10551. doi: 10.1523/JNEUROSCI.3007-12.2013

Koopmans, R., Dingemanse, J., Danhof, M., Horsten, G. P., and van Boxtel, C. J. (1988). Pharmacokinetic-pharmacodynamic modeling of midazolam effects on the human central nervous system. Clin. Pharm. Ther. 44, 14-22. doi: $10.1038 /$ clpt.1988.106

Kopell, N. (2005). Does it have to be this complicated? Focus on "singlecolumn thalamocortical network model exhibiting gamma oscillations, spindles, and epileptogenic bursts". J. Neurophysiol. 93, 1829-1830. doi: 10.1152/jn.01147.2004

Lakatos, P., Barczak, A., Neymotin, S. A., McGinnis, T., Ross, D., Javitt, D. C., et al. (2016). Global dynamics of selective attention and its lapses in primary auditory cortex. Nat. Neurosci. 19, 1707. doi: 10.1038/nn.4386

Lange, J., Keil, J., Schnitzler, A., van Dijk, H., and Weisz, N. (2014). The role of alpha oscillations for illusory perception. Behav. Brain Res. 271, 294-301. doi: 10.1016/j.bbr.2014.06.015

Lieberman, J. A., Mailman, R. B., Duncan, G., Sikich, L., Chakos, M., Nichols, D. E., et al. (1998). Serotonergic basis of antipsychotic drug effects in schizophrenia. Biol. Psychiatry 44, 1099-1117. doi: 10.1016/S0006-3223(98)00187-5

Liley, D. T., Cadusch, P. J., Gray, M., and Nathan, P. J. (2003). Drug-induced modification of the system properties associated with spontaneous human electroencephalographic activity. Phys. Rev. E 68:051906. doi: 10.1103/PhysRevE.68.051906

Link, C. G., Leigh, T. J., and Fell, G. L. (1991). Effects of granisetron and lorazepam, alone and in combination, on the EEG of human volunteers. Br. J. Clin. Pharmacol. 31, 93-97. doi: 10.1111/j.1365-2125.1991. tb03863.x 
Lopes da Silva, F. (1991). Neural mechanisms underlying brain waves: from neural membranes to networks. Electroencephalogr. Clin. Neurophysiol. 79, 81-93. doi: 10.1016/0013-4694(91)90044-5

Lopes da Silva, F. H. L., van Lierop, T. H. M. T., Schrijer, C. F., and van Leeuwen, W. S. (1973a). Essential differences between alpha rhythms and barbiturate spindles: Spectra and thalamo-cortical coherences. Electroencephalogr. Clin. Neurophysiol. 35, 641-645.

Lopes da Silva, F. H., and Storm Van Leeuwen, W. (1977). The cortical source of the alpha rhythm. Neurosci Lett 6(2-3), 237-241, doi: 10.1016/0304-3940(77)90024-6

Lopes da Silva, F. H., van Lierop, T. H. M. T., Schrijer, C. F., and Storm van Leeuwen, W. (1973b). Organization of thalamic and cortical alpha rhythms: Spectra and coherences. Electroencephalogr. Clin. Neurophysiol. 35, 627-639.

Lopes da Silva, F. H., Vos, J. E., Mooibroek, J., and Van Rotterdam, A. (1980). Relative contributions of intracortical and thalamo-cortical processes in the generation of alpha rhythms, revealed by partial coherence analysis. Electroencephalogr. Clin. Neurophysiol. 50, 449-456. doi: 10.1016/0013-4694(80)90011-5

Lorente de Nó, R. (1947). Action potential of the motoneurons of the hypoglossus nucleus. J. Cell Physiol. 29, 207-287.

Lörincz, M. L., Crunelli, V., and Hughes, S. W. (2008). Cellular dynamics of cholinergically induced $\alpha(8-13 \mathrm{~Hz})$ Rhythms in sensory thalamic nuclei in vitro. J. Neurosci. 28, 660-671. doi: 10.1523/JNEUROSCI.4468-07.2008

Lörincz, M. L., Kékesi, K. A., Juhász, G., Crunelli, V., and Hughes, S. W. (2009). Temporal framing of thalamic relay-mode firing by phasic inhibition during the alpha rhythm. Neuron 63, 683-696. doi: 10.1016/j.neuron.2009.08.012

Lozano-Soldevilla, D., ter Huurne, N., and Oostenveld, R. (2016). Neuronal oscillations with non-sinusoidal morphology produce spurious phase-toamplitude coupling and directionality. Front. Comput. Neurosci. 10:87. doi: $10.3389 /$ fncom.2016.00087

Lozano-Soldevilla, D., ter Huurne, N., Cools, R., and Jensen, O. (2014). GABAergic modulation of visual gamma and alpha oscillations and its consequences for working memory performance. Curr. Biol. 24, 2878-2887. doi: 10.1016/j.cub.2014.10.017

Magazzini, L., Muthukumaraswamy, S. D., Campbell, A. E., Hamandi, K., Lingford-Hughes, A., Myers, J. F., et al. (2016). Significant reductions in human visual gamma frequency by the gaba reuptake inhibitor tiagabine revealed by robust peak frequency estimation. Hum. Brain Mapp. 37, 3882-3896. doi: $10.1002 / \mathrm{hbm} .23283$

Marshall, T. R., Esterer, S., Herring, J. D., Bergmann, T. O., and Jensen, O. (2016). On the relationship between cortical excitability and visual oscillatory responses - A concurrent tDCS-MEG study. Neuroimage 140, 41-49. doi: 10.1016/j.neuroimage.2015.09.069

Mathewson, K. E., Lleras, A., Beck, D. M., Fabiani, M., Ro, T., and Gratton, G. (2011). Pulsed out of awareness: EEG alpha oscillations represent a pulsed-inhibition of ongoing cortical processing. Front. Psychol. 2:99. doi: 10.3389/fpsyg.2011.00099

Mazaheri, A., and Jensen, O. (2008). Asymmetric amplitude modulations of brain oscillations generate slow evoked responses. J. Neurosci. 28, 7781-7787. doi: 10.1523/JNEUROSCI.1631-08.2008

Mazaheri, A., and Jensen, O. (2010). Rhythmic pulsing: linking ongoing brain activity with evoked responses. Front. Hum. Neurosci. 4:177. doi: $10.3389 /$ fnhum.2010.00177

Medvedovsky, M., Taulu, S., Bikmullina, R., and Paetau, R. (2007). Artifact and head movement compensation in MEG. Neurol. Neurophysiol. Neurosci 4.

Meyer, S. S., Bonaiuto, J., Lim, M., Rossiter, H., Waters, S., Bradbury, D., et al. (2017). Flexible head-casts for high spatial precision MEG. J. Neurosci. Methods 276, 38-45. doi: 10.1016/j.jneumeth.2016.11.009

Michalareas, G., Vezoli, J., van Pelt, S., Schoffelen, J.-M., Kennedy, H., and Fries, P. (2016). Alpha-beta and gamma rhythms subserve feedback and feedforward influences among human visual cortical areas. Neuron 89, 384-397. doi: 10.1016/j.neuron.2015. 12.018

Millett, D. (2001). Hans berger: from psychic energy to the EEG. Perspect. Biol. Med. 44, 522-542. doi: 10.1353/pbm.2001.0070

Mo, J., Schroeder, C. E., and Ding, M. (2011). Attentional modulation of alpha oscillations in macaque inferotemporal cortex. J. Neurosci. 31, 878-882. doi: 10.1523/JNEUROSCI.5295-10.2011
Moran, R. J., Kiebel, S. J., Stephan, K. E., Reilly, R. B., Daunizeau, J., and Friston, K. J. (2007). A neural mass model of spectral responses in electrophysiology. Neuroimage 37, 706-720. doi: 10.1016/j.neuroimage.2007.05.032

Muñoz-Torres, Z., del Río-Portilla, Y., and Corsi-Cabrera, M. (2011). Diazepam-induced changes in EEG oscillations during performance of a sustained attention task. J. Clin. Neurophysiol. 28, 394-399. doi: $10.1097 /$ WNP.0b013e318227323a

Murakami, S., and Okada, Y. (2006). Contributions of principal neocortical neurons to magnetoencephalography and electroencephalography signals. J. Physiol. 575, 925-936. doi: 10.1113/jphysiol.2006.105379

Muthukumaraswamy, S. D. (2014). The use of magnetoencephalography in the study of psychopharmacology (pharmaco-MEG). J. Psychopharmacol. 28, 815-829. doi: 10.1177/0269881114536790

Muthukumaraswamy, S. D., Carhart-Harris, R. L., Moran, R. J., Brookes, M. J., Williams, T. M., Errtizoe, D., et al. (2013a). Broadband cortical desynchronization underlies the human psychedelic state. J. Neurosci. 33, 15171-15183. doi: 10.1523/JNEUROSCI.2063-13.2013

Muthukumaraswamy, S. D., Myers, J. F. M., Wilson, S. J., Nutt, D. J., Hamandi, K., Lingford-Hughes, A., et al. (2013b). Elevating endogenous GABA levels with GAT-1 blockade modulates evoked but not induced responses in human visual cortex. Neuropsychopharmacology 38, 1105-1112. doi: 10.1038/npp.2013.9

Muthukumaraswamy, S. D., Myers, J. F., Wilson, S. J., Nutt, D. J., LingfordHughes, A., Singh, K. D., et al. (2013c). The effects of elevated endogenous GABA levels on movement-related network oscillations. Neuroimage 66, 36-41. doi: 10.1016/j.neuroimage.2012.10.054

Muthukumaraswamy, S. D., Routley, B., Droog, W., Singh, K. D., and Hamandi, K. (2016). The effects of AMPA blockade on the spectral profile of human early visual cortex recordings studied with non-invasive MEG. Cortex 81, 266-275. doi: 10.1016/j.cortex.2016.03.004

Muthukumaraswamy, S. D., Shaw, A. D., Jackson, L. E., Hall, J., Moran, R., and Saxena, N. (2015). Evidence that Subanesthetic doses of ketamine cause sustained disruptions of NMDA and AMPA-mediated frontoparietal connectivity in humans. J. Neurosci. 35, 11694-11706. doi: 10.1523/JNEUROSCI.0903-15.2015

Niedermeyer, E., and da Silva, F. L. (2005). Electroencephalography: Basic Principles, Clinical Applications, and Related Fields, 5th Edn. Philadelphia, PA; London: Lippincott Williams \& Wilkins.

Nikulin, V. V., Linkenkaer-Hansen, K., Nolte, G., Lemm, S., Müller, K. R., Ilmoniemi, R. J., et al. (2007). A novel mechanism for evoked responses in the human brain. Eur. J. Neurosci. 25, 3146-3154. doi: 10.1111/j.1460-9568.2007.05553.x

Nikulin, V. V., Nikulina, A. V., Yamashita, H., Rossi, E. M., and Kähkönen, S. (2005). Effects of alcohol on spontaneous neuronal oscillations: a combined magnetoencephalography and electroencephalography study. Prog. Neuropsychopharmacol. Biol. Psychiatry 29, 687-693. doi: 10.1016/j.pnpbp.2005.04.014

Nir, Y., Fisch, L., Mukamel, R., Gelbard-Sagiv, H., Arieli, A., Fried, I., et al. (2007). Coupling between neuronal firing rate, gamma LFP, and BOLD fMRI is related to interneuronal correlations. Curr. Biol. 17, 1275-1285. doi: $10.1016 /$ j.cub.2007.06.066

Nutt, D., Wilson, S., Lingford-Hughes, A., Myers, J., Papadopoulos, A., and Muthukumaraswamy, S. (2015). Differences between magnetoencephalographic (MEG) spectral profiles of drugs acting on GABA at synaptic and extrasynaptic sites: a study in healthy volunteers. Neuropharmacology 88, 155-163. doi: 10.1016/j.neuropharm.2014.08.017

Oke, O. O., Magony, A., Anver, H., Ward, P. D., Jiruska, P., Jefferys, J. G., et al. (2010). High-frequency gamma oscillations coexist with low-frequency gamma oscillations in the rat visual cortex in vitro. Eur. J. Neurosci. 31, 1435-1445. doi: 10.1111/j.1460-9568.2010.07171.x

Okun, M., and Lampl, I. (2008). Instantaneous correlation of excitation and inhibition during ongoing and sensory-evoked activities. Nat. Neurosci. 11, 535-537. doi: 10.1038/nn.2105

Oostenveld, R., Fries, P., Maris, E., and Schoffelen, J.-M. (2011). FieldTrip: open source software for advanced analysis of MEG, EEG, and invasive electrophysiological data. Comput. Intell. Neurosci. 2011, 9. doi: $10.1155 / 2011 / 156869$

Osipova, D., Ahveninen, J., Kaakkola, S., Jääskeläinen, I. P., Huttunen, J., and Pekkonen, E. (2003). Effects of scopolamine on MEG spectral power 
and coherence in elderly subjects. Clin. Neurophysiol. 114, 1902-1907. doi: 10.1016/S1388-2457(03)00165-2

Palva, S., and Palva, J. M. (2007). New vistas for $\alpha$-frequency band oscillations. Trends Neurosci. 30, 150-158. doi: 10.1016/j.tins.2007.02.001

Palva, S., and Palva, J. M. (2011). Functional Roles of alpha-band phase synchronization in local and large-scale cortical networks. Front. Psychol. 2:204. doi: 10.3389/fpsyg.2011.00204

Pfurtscheller, G., and Lopes da Silva, F. H. (1999). Event-related EEG/MEG synchronization and desynchronization: basic principles. Clin. Neurophysiol. 110, 1842-1857. doi: 10.1016/S1388-2457(99)00141-8

Pfurtscheller, G., Neuper, C., and Mohl, W. (1994). Event-related desynchronization (ERD) during visual processing. Int. J. Psychophysiol. 16, 147-153. doi: 10.1016/0167-8760(89)90041-X

Puig, M. V., and Gener, T. (2015). Serotonin modulation of prefrontohippocampal rhythms in health and disease. ACS Chem. Neurosci. 6, 1017-1025. doi: 10.1021/cn500350e

Puig, M. V., and Gulledge, A. T. (2011). Serotonin and prefrontal cortex function: neurons, networks, and circuits. Mol. Neurobiol. 44, 449-464. doi: 10.1007/s12035-011-8214-0

Puig, M. V., Watakabe, A., Ushimaru, M., Yamamori, T., and Kawaguchi, Y. (2010). Serotonin Modulates fast-spiking interneuron and synchronous activity in the rat prefrontal cortex through 5-HT1A and 5-HT2A receptors. J. Neurosci. 30, 2211-2222. doi: 10.1523/JNEUROSCI.3335-09.2010

Purdon, P. L., Pierce, E. T., Mukamel, E. A., Prerau, M. J., Walsh, J. L., Wong, K. F., et al. (2013). Electroencephalogram signatures of loss and recovery of consciousness from propofol. Proc. Natl. Acad. Sci. U.S.A. 110, E1142-E1151. doi: $10.1073 /$ pnas. 1221180110

Ramos Reis, P. M., Eckhardt, H., Denise, P., Bodem, F., and Lochmann, M. (2013). Localization of scopolamine induced electrocortical brain activity changes, in healthy humans at rest. J. Clin. Pharmacol. 53, 619-625. doi: 10.1002/jcph.83

Riba, J., Anderer, P., Jané, F., Saletu, B., and Barbanoj, M. J. (2004). Effects of the South American psychoactive beverage Ayahuasca on regional brain electrical activity in humans: a functional neuroimaging study using low-resolution electromagnetic tomography. Neuropsychobiology 50, 89-101. doi: $10.1159 / 000077946$

Riba, J., Anderer, P., Morte, A., Urbano, G., Jan,é, F., Saletu, B., et al. (2002). Topographic pharmaco-EEG mapping of the effects of the South American psychoactive beverage ayahuasca in healthy volunteers. Br. J. Clin. Pharmacol. 53, 613-628. doi: 10.1046/j.1365-2125.2002.01609.x

Rice, J. K., Rorden, C., Little, J. S., and Parra, L. C. (2013). Subject position affects EEG magnitudes. Neuroimage 64, 476-484. doi: 10.1016/j.neuroimage.2012.09.041

Riss, J., Cloyd, J., Gates, J., and Collins, S. (2008). Benzodiazepines in epilepsy: pharmacology and pharmacokinetics. Acta Neurol. Scand. 118, 69-86. doi: 10.1111/j.1600-0404.2008.01004.x

Rivolta, D., Heidegger, T., Scheller, B., Sauer, A., Schaum, M., Birkner, K., et al. (2015). Ketamine dysregulates the amplitude and connectivity of highfrequency oscillations in cortical-subcortical networks in humans: evidence from resting-state magnetoencephalography-recordings. Schizophr. Bull. 41, 1105-1114. doi: 10.1093/schbul/sbv051

Robinson, P. A., Rennie, C. J., Wright, J. J., Bahramali, H., Gordon, E., and Rowe, D. L. (2001). Prediction of electroencephalographic spectra from neurophysiology. Phys. Rev. E 63:021903. doi: 10.1103/PhysRevE.63.021903

Saalmann, Y. B., Pinsk, M. A., Wang, L., Li, X., and Kastner, S. (2012). The pulvinar regulates information transmission between cortical areas based on attention demands. Science 337, 753-756. doi: 10.1126/science.1223082

Saletu, B., Grünberger, J., and Linzmayer, L. (1986). On central effects of serotonin re-uptake inhibitors: quantitative EEG and psychometric studies with sertraline and zimelidine. J. Neural Transm 67, 241-266. doi: 10.1007/BF01243351

Saletu, B., Grünberger, J., Anderer, P., Linzmayer, L., and Zyhlarz, G. (1996). Comparative pharmacodynamic studies with the novel serotonin uptake-enhancing tianeptine and - inhibiting fluvoxamine utilizing EEG mapping and psychometry. J. Neural Transm 103, 191-216. doi: 10.1007/BF01292627

Saletu, B., Grünberger, J., Anderer, P., Linzmayer, L., Semlitsch, H. V., and Magni, G. (1992). Pharmacodynamics of venlafaxine evaluated by EEG brain mapping, psychometry and psychophysiology. Br. J. Clin. Pharmacol. 33, 589-601. doi: $10.1111 /$ j.1365-2125.1992.tb04087.x
Sannita, W. G., Maggi, L., and Rosadini, G. (1987). Effects of scopolamine (0.25$0.75 \mathrm{mg}$ i.m.) on the quantitative EEG and the neuropsychological status of healthy volunteers. Neuropsychobiology 17, 199-205.

Saxena, N., Muthukumaraswamy, S. D., Diukova, A., Singh, K., Hall, J., and Wise, R. (2013). Enhanced Stimulus-induced gamma activity in humans during propofol-induced sedation. PLoS ONE 8:e57685. doi: 10.1371/journal.pone.0057685

Schenberg, E. E., Alexandre, J. F., Filev, R., Cravo, A. M., Sato, J. R., Muthukumaraswamy, S. D., et al. (2015). Acute biphasic effects of ayahuasca. PLoS ONE 10:e0137202. doi: 10.1371/journal.pone.0137202

Schreckenberger, M., Lange-Asschenfeld, C., Lochmann, M., Mann, K., Siessmeier, T., Buchholz, H.-G., et al. (2004). The thalamus as the generator and modulator of EEG alpha rhythm: a combined PET/EEG study with lorazepam challenge in humans. Neuroimage 22, 637-644. doi: 10.1016/j.neuroimage.2004. 01.047

Shaw, A. D., Saxena, N., E., Jackson, L., Hall, J. E., Singh, K. D., and Muthukumaraswamy, S.D. (2015). Ketamine amplifies induced gamma frequency oscillations in the human cerebral cortex. Eur. Neuropsychopharmacol. 25, 1136-1146. doi: 10.1016/j.euroneuro.2015.04.012

Sherman, M. A., Lee, S., Law, R., Haegens, S., Thorn, C. A., Hämäläinen, M. S., et al. (2016). Neural mechanisms of transient neocortical beta rhythms: converging evidence from humans, computational modeling, monkeys, and mice. Proc. Natl. Acad. Sci. U.S.A. 113, E4885-E4894. doi: 10.1073/pnas.16041 35113

Silva, L. R., Amitai, Y., and Connors, B. W. (1991). Intrinsic oscillations of neocortex generated by layer 5 pyramidal neurons. Science 251, 432-435.

Sloan, E. P., Fenton, G. W., and Standage, K. P. (1992). Anticholinergic drug effects on quantitative electroencephalogram, visual evoked potential, and verbal memory. Biol. Psychiatry 31, 600-606. doi: 10.1016/0006-3223(92)90246-V

Smith, D. M., Fisher, D., Blier, P., Ilivitsky, V., and Knott, V. (2016). The separate and combined effects of monoamine oxidase A inhibition and nicotine on resting state EEG. J. Psychopharm. 30, 56-62. doi: 10.1177/0269881115613518

Spaak, E., Bonnefond, M., Maier, A., Leopold, David A., and Jensen, O. (2012). Layer-specific entrainment of gamma-band neural activity by the alpha rhythm in monkey visual cortex. Curr. Biol. 22, 2313-2318. doi: 10.1016/j.cub.2012.10.020

Stam, C. J., Pijn, J. P., Suffczynski, P., and Lopes da Silva, F. H. (1999). Dynamics of the human alpha rhythm: evidence for non-linearity? Clin. Neurophysiol. 110, 1801-1813.

Steriade, M. (1999). "Cellular substrates of brain rhythms," in Electroencephalography Basic Principles, Clinical Applications, and Related Fields., eds E. Niedermeyer and F. H. Lopes da Silva. (Philadelphia, PA: Lippincott Williams and Wilkins), 28-75.

Steriade, M., Gloor, P., Llinás, R. R., Lopes da Silva, F. H., and Mesulam, M. M. (1990). Basic mechanisms of cerebral rhythmic activities. Electroencephalogr. Clin. Neurophysiol. 76, 481-508. doi: 10.1016/0013-4694(90)90001-Z

Stolk, A., Todorovic, A., Schoffelen, J.-M., and Oostenveld, R. (2013). Online and offline tools for head movement compensation in MEG. Neuroimage 68, 39-48. doi: 10.1016/j.neuroimage.2012.11.047

Supp, G. G., Siegel, M., Hipp, J. F., and Engel, A. K. (2011). Cortical hypersynchrony predicts breakdown of sensory processing during loss of consciousness. Curr. Biol. 21, 1988-1993. doi: 10.1016/j.cub.2011.10.017

Taulu, S., Simola, J., and Kajola, M. (2005). Applications of the signal space separation method. IEEE Trans. Signal Process. 53, 3359-3372. doi: $10.1109 /$ TSP.2005.853302

Thiele, A. (2013). Muscarinic signaling in the brain. Annu. Rev. Neurosci. 36, 271-294. doi: 10.1146/annurev-neuro-062012-170433

Thompson, J. C., Tzambazis, K., Stough, C., Nagata, K., and Silberstein, R. B. (2000). The effects of nicotine on the $13 \mathrm{~Hz}$ steady-state visually evoked potential. Clin. Neurophysiol. 111, 1589-1595. doi: $10.1016 /$ S1388-2457(00)00334-5

Thut, G., Nietzel, A., Brandt, S. A., and Pascual-Leone, A. (2006). $\alpha$-band electroencephalographic activity over occipital cortex indexes visuospatial attention bias and predicts visual target detection. J. Neurosci. 26, 9494-9502. doi: 10.1523/JNEUROSCI.0875-06.2006

Tiesinga, P., and Sejnowski, T. J. (2009). Cortical enlightenment: are attentional gamma oscillations driven by ING or PING? Neuron 63, 727-732. doi: 10.1016/j.neuron.2009.09.009 
Timofeev, I., Bazhenov, M., Seigneur, J., and Sejnowski, T. (2012). "Neuronal Synchronization and Thalamocortical Rhythms in Sleep, Wake and Epilepsy," in Jasper's Basic Mechanisms of the Epilepsies, eds J. L. Noebels, M. Avoli, M. A. Rogawski, R. W. Olsen, and A. V. Delgado-Escueta (Bethesda, MD: National Center for Biotechnology Information), 1-30.

Tran, Y., Craig, A., Bartrop, R., and Nicholson, G. (2004). Time course and regional distribution of cortical changes during acute alcohol ingestion. Int. J. Neurosci. 114, 863-878. doi: 10.1080/00207450490450055

Traub, R. D., and Miles, R. (1991). Neuronal Networks of the Hippocampus. New York, NY: Cambridge University Press.

Traub, R. D., and Whittington, M. A. (2010). Cortical Oscillations in Health and Disease. New York, NY: Oxford University Press.

Traub, R. D., Whittington, M. A., and Jefferis, J. G. R. (1999). Fast Oscillations in Cortical Circuits. Cambridge, MA: MIT press.

Traub, R., Whittington, M., Colling, S., Buzsáki, G., and Jefferys, J. G. (1996). Analysis of gamma rhythms in the rat hippocampus in vitro and in vivo. J. Physiol. 493(Pt 2), 471-484. doi: 10.1113/jphysiol.1996.sp021397

Urata, J., Uchiyama, M., Iyo, M., Enomoto, T., Hayakawa, T., Tomiyama, M., et al. (1996). Effects of a small dose of triazolam on P300 and resting EEG. Psychopharmacology 125, 179-184. doi: 10.1007/BF02249418

Valle, M., Maqueda, A. E., Rabella, M., Rodríguez-Pujadas, A., Antonijoan, R. M., Romero, S., et al. (2016). Inhibition of alpha oscillations through serotonin-2A receptor activation underlies the visual effects of ayahuasca in humans. Eur. Neuropsychopharmacol. 26, 1161-1175. doi: 10.1016/j.euroneuro.2016.03.012

van de Nieuwenhuijzen, M. E., van den Borne, E. W., Jensen, O., and van Gerven, M. A. (2016). Spatiotemporal dynamics of cortical representations during and after stimulus presentation. Front. Syst. Neurosci. 10:42. doi: 10.3389/fnsys.2016.00042

van der Meij, R., van Ede, F., and Maris, E. (2016). Rhythmic components in extracranial brain signals reveal multifaceted task modulation of overlapping neuronal activity. PLOS ONE 11:e0154881. doi: 10.1371/journal.pone. 0154881

van Kerkoerle, T., Self, M. W., Dagnino, B., Gariel-Mathis, M.-A., Poort, J., van der Togt, C., et al. (2014). Alpha and gamma oscillations characterize feedback and feedforward processing in monkey visual cortex. Proc. Natl. Acad. Sci. U.S.A. 111, 14332-14341. doi: 10.1073/pnas.1402773111

van Leeuwen, T. H., Verbaten, M. N., Koelega, H. S., Slangen, J. L., van der, G. J., and Camfferman, G. (1995). Effects of oxazepam on eventrelated brain potentials, EEG frequency bands, and vigilance performance. Psychopharmacology 122, 244-262. doi: 10.1007/BF02246546

Van Steveninck, A. L., Mandema, J. W., Tuk, B., Van Dijk, J. G., Schoemaker, H. C., Danhof, M., et al. (1993). A comparison of the concentration-effect relationships of midazolam for EEG-derived parameters and saccadic peak velocity. Br. J. Clin. Pharmacol. 36, 109-115. doi: 10.1111/j.1365-2125.1993.tb04205.x

VanRullen, R. (2016). Perceptual Cycles. Trends Cogn. Sci. 20, 723-735. doi: 10.1016/j.tics.2016.07.006

VanRullen, R., Busch, N. A., Drewes, J., and Dubois, J. (2011). Ongoing EEG phase as a trial-by-trial predictor of perceptual and attentional variability. Front. Psychol. 2:60. doi: 10.3389/fpsyg.2011.00060
Vijayan, S., and Kopell, N. J. (2012). Thalamic model of awake alpha oscillations and implications for stimulus processing. Proc. Natl. Acad. Sci. U.S.A. 109, 18553-18558. doi: 10.1073/pnas.1215385109

Vijayan, S., Ching, S., Purdon, P. L., Brown, E. N., and Kopell, N. J. (2013). Thalamocortical mechanisms for the anteriorization of alpha rhythms during propofol-induced unconsciousness. J. Neurosci. 33, 11070-11075. doi: 10.1523/JNEUROSCI.5670-12.2013

Vlisides, P. E., Bel-Bahar, T., Lee, U., Li, D., Kim, H., Janke, E., et al. (2017). Neurophysiologic Correlates of Ketamine Sedation and AnesthesiaA Highdensity Electroencephalography Study in Healthy Volunteers. Anesthesiology 127, 58-69. doi: 10.1097/ALN.0000000000001671

Walker, D., Mahoney, C., Ilivitsky, V., and Knott, V. J. (2001). Effects of haloperidol pretreatment on the smoking-induced EEG/mood activation response profile. Neuropsychobiology 43, 102-112. doi: 10.1159/000054875

Weisz, N., Hartmann, T., Müller, N., and Obleser, J. (2011). Alpha rhythms in audition: cognitive and clinical perspectives. Front. Psychol. 2:73. doi: $10.3389 /$ fpsyg.2011.00073

Whittington, M. A., Traub, R. D., and Jefferys, J. G. (1995). Synchronized oscillations in interneuron networks driven by metabotropic glutamate receptor activation. Nature 373, 612-615.

Womelsdorf, T., Valiante, T. A., Sahin, N. T., Miller, K. J., and Tiesinga, P. (2014). Dynamic circuit motifs underlying rhythmic gain control, gating and integration. Nat. Neurosci. 17, 1031. doi: 10.1038/nn.3764

Worden, M. S., Foxe, J. J., Wang, N., and Simpson, G. V. (2000). Anticipatory biasing of visuospatial attention indexed by retinotopically specific $\alpha$-Bank electroencephalography increases over occipital cortex. J. Neurosci. 20, RC63.

Xing, D., Shen, Y., Burns, S., Yeh, C.-I., Shapley, R., and Li, W. (2012a). Stochastic generation of gamma-band activity in primary visual cortex of awake and anesthetized monkeys. J. Neurosci. 32, 13873-13880. doi: 10.1523/JNEUROSCI.5644-11.2012

Xing, D., Yeh, C.-I., Burns, S., and Shapley, R. M. (2012b). Laminar analysis of visually evoked activity in the primary visual cortex. Proc. Natl. Acad. Sci. U.S.A. 109, 13871-13876. doi: 10.1073/pnas.1201478109

Yoto, A., Murao, S., Motoki, M., Yokoyama, Y., Horie, N., Takeshima, K., et al. (2012). Oral intake of $\gamma$-aminobutyric acid affects mood and activities of central nervous system during stressed condition induced by mental tasks. Amino Acids 43, 1331-1337. doi: 10.1007/s00726-011-1206-6

Conflict of Interest Statement: The author declares that the research was conducted in the absence of any commercial or financial relationships that could be construed as a potential conflict of interest.

The reviewer XL and handling Editor declared their shared affiliation.

Copyright (C) 2018 Lozano-Soldevilla. This is an open-access article distributed under the terms of the Creative Commons Attribution License (CC BY). The use, distribution or reproduction in other forums is permitted, provided the original author(s) and the copyright owner are credited and that the original publication in this journal is cited, in accordance with accepted academic practice. No use, distribution or reproduction is permitted which does not comply with these terms. 